\title{
Kinetic Study of Low Temperature Sulfur Dioxide Removal Reaction By Sodium Carbonate Using Random Pore Model
}

Iman Omidi

Amirkabir University of Technology Department of Chemical Engineering

Habib Ale Ebrahim ( $\square$ alebrm@aut.ac.ir)

Amirkabir University of Technology Department of Chemical Engineering https://orcid.org/0000-00030947-9444

\section{Research Article}

Keywords: Sodium carbonate, SO2 removal, Kinetic study, Thermogravimetry, Random pore model

Posted Date: March 31st, 2021

DOl: https://doi.org/10.21203/rs.3.rs-324950/v1

License: (c) (i) This work is licensed under a Creative Commons Attribution 4.0 International License.

Read Full License 
4

\section{Kinetic Study of Low Temperature Sulfur Dioxide Removal Reaction by Sodium Carbonate using Random Pore Model}

\author{
Iman Omidi and Habib Ale Ebrahim*
}

\section{Department of Chemical Engineering, Amirkabir University of Technology (Tehran Polytechnic), Tehran, Iran}

\begin{abstract}
An experimental investigation of low temperature $\mathrm{SO}_{2}$ removal by porous sodium carbonate was carried out by thermogravimetry. As well as, applied mathematical modeling based on the random pore model was employed to kinetic study of this reaction. The experiments were performed at various temperatures $\left(100-250{ }^{\circ} \mathrm{C}\right)$ and different $\mathrm{SO}_{2}$ concentrations (0.13-1.12 vol\%). The initial slopes procedure was used to determine dependency of the reaction rate constants versus temperature. First-order kinetic with respect to gaseous reactant was found and value of activation energy was attained as $22.5 \mathrm{~kJ} \mathrm{~mol}^{-1}$. Product layer diffusion coefficients were evaluated by the best fitting of experimental data with the model predictions. These random pore model predictions indicated good agreement with experimental conversion-time data at various conditions. The resulted kinetic parameters were avail abled for engineering calculations of $\mathrm{SO}_{2}$ abatement from the coal-based power plants by low-temperature flue gas desulfurization.
\end{abstract}

\title{
Keywords:
}

Sodium carbonate; $\mathrm{SO}_{2}$ removal; Kinetic study; Thermogravimetry; Random pore model

*: Corresponding author phone/fax: 00982166405847, Amirkabir University of Technology (Tehran Polytechnic), Departement of Chemical Engineering/Non-catalytic gas-solid reactions laboratory, Tehran, Iran, email: alebrm@aut.ac.ir 


\section{Introduction}

\subsection{Background Information}

One of the significant air contaminant which causes acid rain is sulfur dioxide. Sulfuric acid formed by the reaction of $\mathrm{SO}_{2}$ with water vapor in the air generates acid rain afterward. Creation of acidic lakes, reduction of soil fertility, damaging forests, and corrosive results on stones and metals are some of the acid rain's destructive impacts. Therefore, lots of industries require to develop appropriate $\mathrm{SO}_{2}$ removal procedures because of the environmental hazards of this air pollutant.

Power plants based on coal, roasting units of extractive metallurgical plants (copper and zinc) and refineries of natural gas are the sulfur dioxide's major sources (Petheram 2002). Several $\mathrm{SO}_{2}$ emission controller rules are established for the mobile sources. European Union limited the sulfur values in gasoline and gas-oil to $10 \mathrm{ppm}$ since 2010 (Stanislaus et al. 2010). Consequently, modified catalysts have been presented for petroleum fuels hydrotreating (Chen et al. 2010, Yin et al. 2011). As well as to increase $\mathrm{SO}_{2}$ removal yield from the stationary sources, recent studies focused on different Flue Gas Desulfurization (FGD) methods.

FGD technologies include throw-away and regenerative processes (Kirk et al. 1949). Throw-away procedures are suitable for based coal power plants within $1000 \mathrm{ppm} \mathrm{SO}_{2}$ concentrations. The general sorbent in these processes is lime $(\mathrm{CaO})$. However, lime reaction with sulfur dioxide is accomplished at high temperatures (about $800{ }^{\circ} \mathrm{C}$ ). Moreover, incomplete conversion can be occurred owing to pore mouth obstruction $(Z=3)$ (Ale Ebrahim 2010).

In addition, wet and dry regenerative processes are appropriate with high $\mathrm{SO}_{2}$ concentrations in several metallurgical systems. $\mathrm{SO}_{2}$ absorbs by $\mathrm{Na}_{2} \mathrm{SO}_{3}$ solution and strips in wet regenerative FGD method. In dry regenerative FGD method, $\mathrm{CuSO}_{4}$ produced by the reaction of $\mathrm{SO}_{2}$ with $\mathrm{CuO}$. Then, $\mathrm{CuO}$ regenerated with reducing $\mathrm{CuSO}_{4}$ by $\mathrm{H}_{2}$. The concentrated $\mathrm{SO}_{2}$ stream in both regenerative processes should be reduced by methane (Mousavi et al. 2018, Sohn \&Kim 2002).

Metal oxides and metal carbonates are the current adsorbents of throw-away processes consist of $\mathrm{CaO}$ (lime), $\mathrm{MgO}, \mathrm{Na}_{2} \mathrm{CO}_{3}, \mathrm{~K}_{2} \mathrm{CO}_{3}, \mathrm{Fe}_{2} \mathrm{O}_{3}$, etc. The main characteristic of these processes are simplicity of operation and economic efficiency (Gray \&Jarvis 2020, Jia et al. 2007, Tseng \&Wey 

2004). Major advantage of sodium carbonate is its ability to remove $\mathrm{SO}_{2}$ at low temperatures (about $200{ }^{\circ} \mathrm{C}$ ). The $\mathrm{Na}_{2} \mathrm{CO}_{3}$ sorbent base FGD reaction can be written as:

$$
\mathrm{Na}_{2} \mathrm{CO}_{3}+\mathrm{SO}_{2}+0.5 \mathrm{O}_{2} \rightarrow \mathrm{Na}_{2} \mathrm{SO}_{4}+\mathrm{CO}_{2}
$$

\subsection{Literature Review}

To investigate performance of sulfur dioxide removal by sodium carbonate several experimental studies have been done in the literature.

Dry sodium injection has been studied by the Electric Power Research Institute (EPRI) since 1977. This material tested as a solid sorbent (Bland 1990). The related test results demonstrate that $\mathrm{SO}_{2}$ reduce $70-90 \%$ for subbituminous coals combustion with a different sorbents based on sodium, which all of them contain a considerable ratio of sodium bicarbonate.

Several studies were conducted to investigate the influence of $\mathrm{NaHCO}_{3}$ thermal decomposition to $\mathrm{Na}_{2} \mathrm{CO}_{3}$ on $\mathrm{SO}_{2}$ absorption efficiency (Carson 1980, Dal Pozzo et al. 2019, Erdos et al. 1989, Knight 1977, Mocek \&Beruto 1986). These reports indicated that gas temperatures between 120$175{ }^{\circ} \mathrm{C}$ showed the best performance for $\mathrm{SO}_{2}$ scrubbing when the initial substance is sodium bicarbonate.

Han et al. described for the first time that $\mathrm{Na}_{2} \mathrm{CO}_{3}$ additive can promote the sulfate conversion of limestone due to the enhanced surface area and tuned pore size distribution (Han et al. 2017). A packed scrubber with absorbents (limestone and sodium bicarbonate) was used by Ghorbani et al. to measure the concentration of sulfur dioxide at the inlet and outlet of scrubber. The results presented the more $\mathrm{SO}_{2}$ removal efficiency by using these absorbents with cation surfactants (ghorbani shahna et al. 2017).

A non-isothermal thermogravimetric analysis was used by $\mathrm{Wu}$ et al. to determine the intrinsic kinetics of the $\mathrm{NaHCO}_{3}$ to $\mathrm{Na}_{2} \mathrm{CO}_{3}$ decomposition reaction. They reported activation energy as $25.3 \mathrm{kcal} \mathrm{mol}^{-1}$ for sodium bicarbonate decomposition. They found that elevating the temperature of decomposition from 120 to $230{ }^{\circ} \mathrm{C}$ enhances pore diameter from 180 to $210 \mathrm{~nm}$ (Wu \&Shih 1993). 
81 Mortson et al. applied regenerated sodium bicarbonate/carbonate to remove $\mathrm{SO}_{2}$ and $\mathrm{NO}_{\mathrm{x}}$ using an advance and economic FGD technology developed by AIRborne Technologies Inc. (ATI). High $\mathrm{SO}_{2}$ removal yield and production of different fertilizers reported in this work (Mortson \&Telesz 2001).

Guangwen et al. used a powder-particle fluidized bed reactor to absorb $\mathrm{SO}_{2}$ and NO by $\mathrm{Na}_{2} \mathrm{CO}_{3} / \mathrm{Al}_{2} \mathrm{O}_{3}$. As well as they examined different effective parameters, such as reaction temperature, fraction of mixtures in flue gas, and sorbent size (Xu et al. 2000).

Walawska et al. studied on structural factors of particle. In addition, mechanically and thermally activated sodium bicarbonate were considered. Sodium carbonate showed better removal yield than sodium bicarbonate (Walawska et al. 2014).

Ma et al. presented a concept test of NOXSO flue gas treatment process at three scales of 0.017, 0.06 and 0.75 MW power plants (Ma \&Haslbeck 1993).

To explain the $\mathrm{NaHCO}_{3}$ and $\mathrm{SO}_{2}$ reaction, Keener et al. employed shrinking core model (with neglecting solid reactant porosity). In order to deduce the rate constant expression, kinetic data were exported from this model. The measured activation energy $\left(56.4 \mathrm{kJmol}^{-1}\right)$ indicates dependency of rate constant to temperature (Keener \&Khang 1993).

Kimura et al. studied the $\mathrm{SO}_{2}-\mathrm{Na}_{2} \mathrm{CO}_{3}$ reaction kinetics in the range of 80-140 ${ }^{\circ} \mathrm{C}$, constant $\mathrm{SO}_{2}$ concentration of $0.3 \%$ with thermogravimetric analysis data. Because of rapid reaction, particular precautions were affected to operate such that transport resistance did not change the results. Rate constants were estimated from the suggested mechanism and the experimental data (Kimura \&Smith 1987). However, $\mathrm{SO}_{2}$ diffusion resistance between $\mathrm{Na}_{2} \mathrm{CO}_{3}$ nano-grains was neglected (Kimura \&Smith 1987).

Ebrahimi et al. developed a model based on film theory for the $\mathrm{SO}_{2}$ removal by $\mathrm{NaHCO} / \mathrm{Na}_{2} \mathrm{CO}_{3}$ solution in a packed tower. This model includes diffusion and reaction processes, also thermodynamic equilibrium was considered for reactants in the bulk fluid (Ebrahimi et al. 2003).

Prada et al. designed a fixed-bed reactor to remove $\mathrm{SO}_{2}$ in flue gases with sodium bicarbonate. Experiments were performed for $1500 \mathrm{ppm} \mathrm{SO}_{2}$ and temperatures above $122{ }^{\circ} \mathrm{C}$. In addition, a solution technique was used to predict the performance of reaction in this system with respect to 
the length of reactor. This work showed better economic efficiency than $\mathrm{SO}_{2}$ elimination with activated carbon for small-scale FGD applications (Charry Prada et al. 2019).

\subsection{Goals and Importance of the Present Study}

As mentioned, lime-based FGD systems are only performed at high temperatures (about $800{ }^{\circ} \mathrm{C}$ ). In addition, incomplete conversion phenomenon of $\mathrm{CaO}$ reaction with $\mathrm{SO}_{2}$ occurs due to pore mouth blockage (gypsum molar volume is very higher than lime, or $\mathrm{Z}=3$ ). Therefore, lime consumption is high and lime/gypsum mixture cannot be used as a byproduct. On the other hand, $\mathrm{Na}_{2} \mathrm{CO}_{3}$ can remove $\mathrm{SO}_{2}$ at low temperatures (about $200{ }^{\circ} \mathrm{C}$ ). Other advantage of $\mathrm{Na}_{2} \mathrm{CO}_{3}$ FGD system is its lower $\mathrm{Z}$ value $(\mathrm{Z}=1.28)$, which means high possibility of complete conversion in $\mathrm{Na}_{2} \mathrm{CO}_{3}$ reaction with $\mathrm{SO}_{2}$. Consequently, $\mathrm{SO}_{2}$ removal by $\mathrm{Na}_{2} \mathrm{CO}_{3}$ can be accomplished in low temperature flue gas ducts and sorbent consumption is low due to complete conversions.

To kinetic studies of non-catalytic gas-solid reactions, several mathematical models such as Modified grain model and RPM have been applied yet. These models can predict alteration of solid structural and specifically partial conversion. Really, industrial sorbents react on the interior areas of pores with a pore size distribution (PSD). Modified grain model simplification assumption is considering of porous solid contains of uniform fine grains which reaction occurs on their surfaces. It was confirmed that RPM accuracy for predicting conversion-time profiles is higher than modified grain model, due to considering of real PSD of the porous sorbent (Bahrami et al. 2015).

As expressed in section 1.2, literature kinetic studies on the reaction of $\mathrm{Na}_{2} \mathrm{CO}_{3}$ with $\mathrm{SO}_{2}$ are very scarce. For example, Keener et al. (Keener \&Khang 1993) applied sharp interface model for this reaction, while the resulted kinetic parameters seem insecure due to neglecting internal surfaces of sodium carbonate sorbent. On the other hand, Kimura et al. (Kimura \&Smith 1987) considered a porous model, while neglecting diffusion resistance between $\mathrm{Na}_{2} \mathrm{CO}_{3}$ nano-grains is questionable. Ultimately, comprehensive kinetic study of $\mathrm{SO}_{2}$ reaction with $\mathrm{Na}_{2} \mathrm{CO}_{3}$ which is not accomplished until now, is highly necessary for determining accurate inherent kinetic parameters. Therefore, the scope of the present work is complete kinetic study of $\mathrm{SO}_{2}$ reaction with $\mathrm{Na}_{2} \mathrm{CO}_{3}$ using sophisticated RPM considering concentration dependency and using real PSD of the porous solid. The resulted kinetic parameters are required for design of low temperature FGD reactors. 
In this study, to determine the conversion-time profile data of $\mathrm{Na}_{2} \mathrm{CO}_{3}$ reaction with $\mathrm{SO}_{2}$, isothermal thermogravimetry was used at predefined concentrations and temperatures. Moreover, precise modelling of $\mathrm{Na}_{2} \mathrm{CO}_{3}$ reaction with $\mathrm{SO}_{2}$ is carried out by RPM. To evaluate the PSD, mercury porosimetry and nitrogen adsorption were applied. As well as, the appropriate order of the reaction is estimated. Initial slopes of conversion-time curves at several temperatures are used to determine intrinsic rate constants. The whole conversion-time profiles are employed to estimate the product layer diffusion coefficients. The comparison between measured RPM data and experimental data at various operating conditions displayed good agreement eventually.

\section{Materials and Methods}

\subsection{Raw Materials}

To kinetic study of this reaction, pure sodium bicarbonate powder (Chem-Lab) was used as the starting material. $85 \mathrm{mg}$ pellets were constructed in a $10 \mathrm{~mm}$ diameter cylindrical mould by 6 bar hydraulic press with $1 \mathrm{~mm}$ thickness. The slab pellet was placed in a thermogravimeter and was heated up to temperature range of $100-250{ }^{\circ} \mathrm{C}$ for 30 minutes. Thus, a porous sodium carbonate pellet ready for reaction with different sulfur dioxide concentrations was prepared by thermal decomposition. The high porosity of the pellet is due to the release of water and carbon dioxide during this calcination step. The gaseous mixture of zero air and $\mathrm{SO}_{2}(99.95 \%)$ was used as a reactant in this study.

\subsection{Equipment}

A Rheometric Scientific thermogravimeter (TG) was employed in this work that can operate at an isothermal condition with $1^{\circ} \mathrm{C}$ deviation. An experimental setup's schematic diagram is provided in Fig. 1. The slab pellets contact better with gaseous stream in TG by placing in a platinum basket. Zero air stream $\left(150 \mathrm{~cm}^{3} \mathrm{~min}^{-1}\right)$ was utilized to purge the TG furnace and the sample was heated by a rate of $30{ }^{\circ} \mathrm{C} \cdot \mathrm{min}^{-1}$ to attain the reaction temperature. Then, the calcination was carried out in reaction temperature for 30 minutes. As a result, an extremely porous sodium carbonate pellet was provided. Then, in an isothermal step, a mixture of $\mathrm{SO}_{2}$ and zero air was injected into TG at a pre- 
defined concentration. Thus, $\mathrm{Na}_{2} \mathrm{CO}_{3}$ reacted by $\mathrm{SO}_{2}$ and $\mathrm{TG}$ device measured the weight changes of the pellet at various constant temperatures.

\subsection{Sample Characterization}

Nitrogen adsorption by Autosorb-1MP from Quantachrome for determination the micro and mesopores of the pellet (by a 55-point test) and mercury porosimetry for evaluation of macropores were utilized to obtain the $\mathrm{Na}_{2} \mathrm{CO}_{3}$ pellet's whole PSD. Two methods, Horvath-Kawazoe (HK) and Barrett-Joyner-Halenda (BJH), were used for calculating the volume of micropores and mesopores from the nitrogen adsorption test. Furthermore, Washburn equation was used for evaluation of macropores from mercury porosimetry test. Consequently, the whole PSD of the porous $\mathrm{Na}_{2} \mathrm{CO}_{3}$ pellet in the range of $0.3-1000 \mathrm{~nm}$ was obtained which is presented in Fig. 2.

Fig. 3 displays the SEM pictures of the raw slab, after calcination at $150{ }^{\circ} \mathrm{C}$, after reaction with $\mathrm{SO}_{2}$ at $150{ }^{\circ} \mathrm{C}$ (52\% conversion), and $225^{\circ} \mathrm{C}(75 \%$ conversion). It is obvious from this figure that due to the release of $\mathrm{CO}_{2}$ and $\mathrm{H}_{2} \mathrm{O}$ molecules from the sample, porosity increased after calcination. Then, owing to formation of the product layer around the pores, porosity decreased during the reaction of the pellet with $\mathrm{SO}_{2}$. In addition, the reduction in the pellet porosity at $225{ }^{\circ} \mathrm{C}$ is more significant than $150{ }^{\circ} \mathrm{C}$, due to the higher reaction rate and higher product layer thickness.

Finally, the XRD pattern of reacted pellet showed both $\mathrm{Na}_{2} \mathrm{CO}_{3}$ and $\mathrm{Na}_{2} \mathrm{SO}_{4}$ phases, which emphasized the ability to react and removal of $\mathrm{SO}_{2}$ by $\mathrm{Na}_{2} \mathrm{CO}_{3}$.

\section{Kinetic Modeling}

The most sophisticated RPM model which was originally demonstrated by Bhatia and Perlmutter (Bhatia \&Perlmutter 1981) is employed for precise kinetic study by considering different pore diameters and structural alteration (Moshiri et al. 2014, Ramachandran \&Doraiswamy 1982). The assumptions of this model are the pseudo-steady state for gas concentration, the irreversible reaction, negligible effect of the bulk flow, the isothermal system and constant size of the pellet (Ale Ebrahim 2010, Bahrami et al. 2014). The dimensionless differential equations for a slab pellet 
192 and an arbitrary concentration dependency are as follows (Bahrami et al. 2014, Bahrami et al. 193 2016):

$194 \frac{\partial}{\partial y}\left(\delta \frac{\partial a}{\partial y}\right)=\frac{\phi^{2} f(a) b \sqrt{1-\psi \ln b}}{1+\frac{\beta Z}{\psi}[\sqrt{1-\psi \ln b}-1]}$

$195 \frac{\partial b}{\partial \theta}=-\frac{f(a) b \sqrt{1-\psi \ln b}}{1+\frac{\beta Z}{\psi}[\sqrt{1-\psi \ln b}-1]}$

196 Where, dimensionless gaseous and solid reactants concentration are a and $b$, the initial Thiele 197 modulus is $\varphi$, the main RPM parameter which is the initial pore size distribution's function of the 198 calcined slab is $\psi$, and the product layer's diffusion resistance is $\beta$. The initial and boundary 199 conditions of the above equations are expressed as:

$200 \quad \theta=0 \rightarrow b=1$

$201 \quad y=0 \rightarrow \frac{\partial a}{\partial y}=0$

$202 \quad y=1 \rightarrow \frac{\partial a}{\partial y}=\frac{S h}{\delta}(1-a)$

203 The local pellet porosity varies by time and described as (Bahrami et al. 2016, Moshiri et al. 2014):

$204 \frac{\varepsilon}{\varepsilon_{0}}=1-\frac{(Z-1)\left(1-\varepsilon_{0}\right)(1-b)}{\varepsilon_{0}}$

205 To relate the dimensionless effective pore diffusion and pellet porosity, following equation is used 206 (Bahrami et al. 2016, Moshiri et al. 2014):

$207 \delta=\frac{D_{e}}{D_{e 0}}=\left(\frac{\varepsilon}{\varepsilon_{0}}\right)^{2}=\left[1-\frac{(Z-1)\left(1-\varepsilon_{0}\right)(1-b)}{\varepsilon_{0}}\right]^{2}$ 
208 The effective initial pore diffusion $\left(D_{e_{0}}\right)$ is calculated from molecular diffusion determined by the 209 Chapman-Enskog equation $\left(D_{A M}\right)$, and Knudsen diffusion equation based on the average pore size $210\left(D_{A K}\right)$, by the following equations (Bahrami et al. 2016, Liu \&Wang 2019):

$211 \quad \frac{1}{D_{e_{0}}}=\frac{1}{\varepsilon_{0}^{2}}\left(\frac{1}{D_{A M}}+\frac{1}{D_{A K}}\right)$

$212 D_{A M}=\frac{1.859 \times 10^{-3} T^{1.5} \sqrt{\frac{1}{M_{1}}+\frac{1}{M_{2}}}}{p \sigma_{12}^{2} \Omega}$

$213 \quad D_{A K}=\frac{2 r_{a v}}{3} \sqrt{\frac{8 R_{g} T}{\pi M_{A}}}$

214 The main parameters of RPM is computed using the PSD curve by the following equations

215 (Bahrami et al. 2016):

$216 \quad V_{p}=\int_{0}^{\infty} v_{0}(r) d r$

$217 \quad \varepsilon_{0}=\frac{V_{p}}{V_{p}+\frac{1}{\rho_{B}}}$

$218 \quad r_{a v}=\frac{1}{V_{p}+\frac{1}{\rho_{B}}} \int_{0}^{\infty} v_{0}(r) r d r$

$219 S_{0}=\frac{2}{V_{p}+\frac{1}{\rho_{B}}} \int_{0}^{\infty} \frac{v_{0}(r)}{r} d r$

$220 \quad L_{0}=\frac{1}{\pi\left(V_{p}+\frac{1}{\rho_{B}}\right)} \int_{0}^{\infty} \frac{v_{0}(r)}{r^{2}} d r$ 
$221 \quad \psi=\frac{4 \pi L_{0}\left(1-\varepsilon_{0}\right)}{S_{0}^{2}}$

222 The resulting structural parameters for the calcinated $\mathrm{Na}_{2} \mathrm{CO}_{3}$ pellet from $\mathrm{NaHCO}_{3}$ are given in 223 Table 1.

224 The conversion of slab pellet can be determined as follows (Bahrami et al. 2016, Moshiri et al. 225 2014):

$226 X(\theta)=1-\int_{0}^{1} b(y, \theta) d y$

227 In this study, the finite element method is used for solving the coupled nonlinear partial differential 228 equations of RPM.

229

\section{Results and Discussion}

\subsection{TG and Conversion-Time Results}

232 Typical experimental TG curves of sodium bicarbonate calcination as well as $\mathrm{Na}_{2} \mathrm{CO}_{3}$ reaction 233 with $\mathrm{SO}_{2}$ at 150 and $200{ }^{\circ} \mathrm{C}$ are presented in Figs. 4 and 5. As mentioned pictures show, the first 234 stage were heating of sample pellet under zero air stream to reach the specified reaction 235 temperatures. Through this calcination step, sample weight diminished and porosity of the pellet 236 increased. So a high porous $\mathrm{Na}_{2} \mathrm{CO}_{3}$ pellet was produced due to release of $\mathrm{CO}_{2}$ and $\mathrm{H}_{2} \mathrm{O}$ which 237 was the reason for about $37 \%$ weight loss of initial sample weight. In the next stage, the stream 238 was shifted to a combination of zero air and predefined $\mathrm{SO}_{2}$ concentration. As a result, the sample 239 weight increased due to the sulfation reaction at isothermal condition of TG. During the reaction, 240 the slope of TG curve decreased gradually because of the product layer's thickness increasing.

\section{$241 \quad 4.2$ Concentration Dependency Determination}

242 To determine the best reaction's order, several experiments with $\mathrm{SO}_{2}$ concentrations of $0.13,0.33$, 2430.66 , and 1.12 vol\% were carried out at $150^{\circ} \mathrm{C}$. So, the conversion-time data are plotted in Fig. 6. 244 According to this figure, the conversion increased by raising $\mathrm{SO}_{2}$ mole fraction. As expected, the 
245 pore diffusion and surface reaction controlled the overal rate during the initial stages, while in the 246 next slower stages the reaction rate controlled by product layer diffusion.

247 Now, the RPM equations were solved by considering $\delta=b=1$ at zero time to determine the initial 248 conversion-time slopes. Therefore, equation 1 can be simplified to (Bahrami et al. 2016, Moshiri 249 et al. 2014, Rashidi et al. 2013):

$250 \quad \frac{\partial}{\partial y}\left(\frac{\partial a}{\partial y}\right)=\phi^{2} f(a)$

251 The dimensionless gas concentration profile, $\mathrm{F}(\mathrm{y})$, inserted in equation 2 and integrated to:

$252 b_{\theta \rightarrow 0}=1-F(y) \theta$

253 As a result, conversion at initial time for a slab pellet by using equation 20 and 18 was obtained as 254 follows:

$255 \quad X_{\theta \rightarrow 0}=\int_{0}^{1} F(y) \theta d y$

256 The following equation by differentiation of equation 21 at initial time was obtained:

$257 \quad\left[\frac{d X}{d \theta}\right]_{\theta \rightarrow 0}=\int_{0}^{1} F(y) d y$

258 The dimensionless time was replaced in equation 22 as following (Bahrami et al. 2016, Moshiri et 259 al. 2014, Rashidi et al. 2013):

$260 I=\frac{C_{B 0}\left(1-\varepsilon_{0}\right)}{S_{0} \int_{0}^{1} F(y) d y}\left[\frac{d X}{d t}\right]_{t \rightarrow 0}=k_{s} C_{A b}^{n}$

261 In equation 19, $f(a)$ is the power law or fractional concentration dependency. To solve these 262 equations, the numerical analysis with iteration procedure was used. In this study, (I) was plotted 263 versus $\left(C_{A b}^{n}\right)$ for reaction order between 0.89 and 1.15. The highest regression coefficient was 264 observed in the fractional form. Furthermore, $K_{a d}$ in the denominator was set to get the best results. 
$265 \quad f(a)=\frac{a}{1+K_{a d} C_{A b} a}$

266 The results are summarized in Table 2. It is clear from this table, that the best regression coefficient

267 is related to fractional concentration dependency. Because of the low $\mathrm{SO}_{2}$ concentrations

$268\left(1>>K_{a d} C_{A b} a\right)$, the reaction can be assumed first order.

269

270

271

272

273

274

275

$\left[\frac{d X}{d t}\right]_{t \rightarrow 0}=\frac{k_{s} S_{0} C_{A b}}{C_{B 0}\left(1-\varepsilon_{0}\right)}\left[\frac{\tanh \left(\frac{L_{0}}{2} \sqrt{\frac{k_{s} S_{0}}{v_{B} D_{e 0}}}\right)}{\frac{L_{0}}{2} \sqrt{\frac{k_{s} S_{0}}{v_{B} D_{e 0}}}}\right]$

276 The calculated rate constants of $\mathrm{Na}_{2} \mathrm{CO}_{3}$ reaction with $0.66 \mathrm{vol} \% \mathrm{SO}_{2}$ at different temperatures are

277 reported in Table 3. The frequency factor and activation energy can be evaluated by the Arrhenius 278 plot that is presented in Fig. 8. So, the rate constant was described as follows:

279

$k_{s}=1.8 \times 10^{-2} \exp \left(\frac{-22486.04}{R T}\right)$

\subsection{Product Layer Diffusion Estimation}

281 To obtain the $D_{p}$ suitable values at various temperatures, the RPM conversion-time curves were

282 plotted by equations 2 and 3 numerically solving and plots was matched with the experimental 283 data. The upward and downward shifts in model conversion-time profiles are gained by higher and 284 lower $D_{p}$ values, respectively.

Table 4 presents the essential parameters for RPM model at $150{ }^{\circ} \mathrm{C}$. In this table, the low value of 286 Thiele modulus illustrates that the system is not completely controlled by diffusion, and the 
287 accuracy of rate constants is appropriate. Fig. 9 shows a successful comparison between RPM

288 predictions and experimental conversion-time profile at various operating temperatures. As 289 demonstrated in this figure, simulation results predicts experimental data with good agreement.

290 Table 5 presents the appropriate $D_{p}$ values. It is obvious that the $D_{p}$ increases with temperature. 291 The diffusion coefficient's Arrhenius plot is illustrated in Fig. 10. The frequency factor and 292 apparent activation energy were found by regression on this diagram between $100-250{ }^{\circ} \mathrm{C}$. Thus, 293 the product layer diffusion is described as a function of temperature with the following expression:

$294 \quad D_{P}=3 \times 10^{-15} \exp \left(\frac{-23354.03}{R T}\right)$

\section{Conclusion}

297 In this study, the kinetics of sulfur dioxide removal reaction by $\mathrm{Na}_{2} \mathrm{CO}_{3}$ was comprehensively 298 carried out by RPM. An isothermal TG was employed for experiments between $100-250{ }^{\circ} \mathrm{C}$ and 299 0.13-1.12 vol\% $\mathrm{SO}_{2}$. The RPM as the most sophisticated mathematical model was applied to 300 generate kinetic parameters of $\mathrm{SO}_{2}$ reaction by $\mathrm{Na}_{2} \mathrm{CO}_{3}$. The RPM considers solid reactant PSD, 301 structural changes, solid reactant pore diffusion, and resistance of product layer. Nitrogen 302 adsorption and mercury porosimetry methods were utilized to plot the complete PSD of the sample. 303 The reaction relation with concentration and temperature were investigated by initial slopes 304 procedure. As a result, the first-order concentration relationship can express the kinetics of the 305 reaction with activation energy of $22.5 \mathrm{~kJ} \mathrm{~mol}^{-1}$. In addition, diffusion coefficients through product 306 layer were specified. RPM predictions follows experimental data with a good agreement. Finally, 307 industrial low temperature FGD plants can be designed by the obtained kinetic parameters.

\section{Nomenclature}

$$
\begin{array}{ll}
a=C_{A} / C_{A b} & \text { Dimensionless gas concentration } \\
b=C_{B} / C_{B 0} & \text { Dimensionless solid concentration }
\end{array}
$$




\begin{tabular}{|c|c|}
\hline$C_{A}$ & Gaseous reactant concentration in the pellet, $\mathrm{kmol} \mathrm{m}^{-3}$ \\
\hline$C_{A b}$ & Bulk gas concentration, $\mathrm{kmol} \mathrm{m}^{-3}$ \\
\hline$C_{B}$ & Solid reactant concentration, $\mathrm{kmol} \mathrm{m}^{-3}$ \\
\hline$C_{B 0}$ & Initial solid reactant concentration, $\mathrm{kmol} \mathrm{m}^{-3}$ \\
\hline$D_{\mathrm{AK}}$ & Knudsen diffusivity, $\mathrm{m}^{2} \mathrm{~s}^{-1}$ \\
\hline$D_{\mathrm{AM}}$ & Molecular diffusivity of gas $\mathrm{A}$ in the pellet, $\mathrm{m}^{2} \mathrm{~s}^{-1}$ \\
\hline$D_{e}$ & Effective diffusivity of gas $\mathrm{A}$ in the pellet, $\mathrm{m}^{2} \mathrm{~s}^{-1}$ \\
\hline$D_{e 0}$ & Initial effective diffusivity of gas $\mathrm{A}$ in the pellet, $\mathrm{m}^{2} \mathrm{~s}^{-1}$ \\
\hline$D_{\mathrm{p}}$ & Effective diffusivity of gas $\mathrm{A}$ in the product layer, $\mathrm{m}^{2} \mathrm{~s}^{-1}$ \\
\hline$k_{\mathrm{m}}$ & External mass transfer coefficient, $\mathrm{m} \mathrm{s}^{-1}$ \\
\hline$k_{\mathrm{s}}$ & Surface rate constant, $\mathrm{m} \mathrm{s}^{-1}$ \\
\hline$K_{a d}$ & Adsorption constant, $\mathrm{m}^{3} \mathrm{kmol}^{-1}$ \\
\hline$L$ & Thickness of the pellet, $\mathrm{m}$ \\
\hline$L_{0}$ & Pore length per unit volume, $\mathrm{m}^{-2}$ \\
\hline$M_{\mathrm{B}}$ & Molecular weight of solid reactant, $\mathrm{kg} \mathrm{kmol}^{-1}$ \\
\hline$M_{\mathrm{D}}$ & Molecular weight of solid product, $\mathrm{kg} \mathrm{kmol}^{-1}$ \\
\hline$n$ & Reaction order \\
\hline$r$ & Pore radius, $\mathrm{m}$ \\
\hline $\bar{r}$ & Average pore radius of the pellet, $\mathrm{m}$ \\
\hline$R^{2}$ & Correlation coefficient \\
\hline$R$ & Gas constant, $\mathrm{J} \mathrm{K}^{-1} \mathrm{~mol}^{-1}$ \\
\hline$S_{0}$ & Reaction surface area per unit volume, $\mathrm{m}^{-1}$ \\
\hline
\end{tabular}




$$
S h=\frac{k_{m} L}{2 D_{A M}}
$$$$
t
$$$$
U_{0}(r)
$$$$
V_{p}
$$$$
X(\theta)
$$$$
y=2 z / L
$$$$
\mathrm{Z}
$$$$
\text { Z }
$$$$
\beta=2 k_{s}\left(1-\varepsilon_{0}\right) /\left(v_{B} D_{p} S_{0}\right)
$$$$
\varepsilon
$$$$
\varepsilon_{0}
$$$$
\delta=\frac{D_{e}}{D_{e 0}}
$$$$
\theta=k_{s} S_{0} C_{A b}^{n} t /\left[C_{B 0}\left(1-\varepsilon_{0}\right]=t / \tau\right.
$$$$
V_{B}
$$$$
v_{D}
$$$$
\rho_{B}
$$$$
\rho_{D}
$$$$
\phi=(L / 2)\left(k_{s} S_{0} C_{A b}^{n-1} / v_{B} D_{e 0}\right)^{1 / 2}
$$$$
\psi
$$

Sherwood number for external mass transfer

Time, $\mathrm{s}$

Pore volume distribution function, $\mathrm{m}^{2} \mathrm{~kg}^{-1}$

Total pore volume, $\mathrm{m}^{3} \mathrm{~kg}^{-1}$

Solid conversion at each time

Dimensionless position in the pellet

Distance from the centre of the pellet, $\mathrm{m}$

Ratio of molar volume of solid product to solid reactant

Product layer resistance

Pellet porosity

Initial pellet porosity

Variation ratio of the pore diffusion

Dimensionless time

Stoichiometric coefficient of the solid reactant

Stoichiometric coefficient of the solid product

True density of the solid reactant, $\mathrm{kg} \mathrm{m}^{-3}$

True density of the solid product, $\mathrm{kg} \mathrm{m}^{-3}$

Thiele modulus for the pellet

Main RPM parameter 


\section{Declarations}

311 Ethics approval and consent to participate: Not applicable

312 Consent for publication: Not applicable

313 Availability of data and materials: The datasets used and/or analyzed during the current study are 314 available from the corresponding author on reasonable request.

315 Competing interests: The authors declare that they have no competing interests.

316 Funding: No funding was received for conducting this study.

317 Authors' contributions: Habib Ale Ebrahim is supervisor of this study. Iman Omidi acquired the data. All 318 authors read and approved the final manuscript.

\section{References}

Ale Ebrahim H (2010): Application of random-pore model to SO2 capture by lime. Industrial \& engineering chemistry research $49,117-122$

Bahrami R, Ebrahim HA, Halladj R (2014): Application of random pore model for SO2 removal reaction by CuO. Process Safety and Environmental Protection 92, 938-947

Bahrami R, Ebrahim HA, Halladj R (2015): Comparison of random pore model, modified grain model, and volume reaction model predictions with experimental results of SO2 removal reaction by $\mathrm{CuO}$. Journal of Industrial and Engineering Chemistry 30, 372-378

Bahrami R, Ebrahim HA, Halladj R, Afshar A (2016): A comprehensive kinetic study of the SO2 removal reaction by pure $\mathrm{CuO}$ with the random pore model. Progress in Reaction Kinetics and Mechanism 41, 385-397

Bhatia S, Perlmutter D (1981): A random pore model for fluid-solid reactions: II. Diffusion and transport effects. AlChE Journal 27, 247-254

Bland V (1990): Evaluation of dry sodium sorbent utilization in combustion gas SOx/NOx reduction. Electric Power Research Institute

Carson JR (1980): Removal of sulfur dioxide and nitric oxide from a flue gas stream by two sodium alkalis of various sizes.

Charry Prada ID, Rivera-Tinoco R, Bouallou C (2019): Flue gas desulfurization assessment by modeling and experimental work of an optimized fixed-bed $\mathrm{NaHCO} 3$ reactor. Industrial \& Engineering Chemistry Research 58, 18717-18730

Chen T-M, Wang C-M, Wang I, Tsai T-C (2010): Promoter effect of vanadia on Co/Mo/Al2O3 catalyst for deep hydrodesulfurization via the hydrogenation reaction pathway. Journal of Catalysis 272, 2836 
Dal Pozzo A, Moricone R, Tugnoli A, Cozzani V (2019): Experimental investigation of the reactivity of sodium bicarbonate toward hydrogen chloride and sulfur dioxide at low temperatures. Industrial \& Engineering Chemistry Research 58, 6316-6324

Ebrahimi S, Picioreanu C, Kleerebezem R, Heijnen J, Van Loosdrecht M (2003): Rate-based modelling of $\mathrm{SO} 2$ absorption into aqueous $\mathrm{NaHCO} 3 / \mathrm{Na} 2 \mathrm{CO} 3$ solutions accompanied by the desorption of $\mathrm{CO} 2$. Chemical engineering science 58, 3589-3600

Erdos E, Mocek K, Lippert E, Uchytilova V, Neuzil L (1989): Application of the active soda process for removing sulphur dioxide from flue gases. JAPCA 39, 1206-1209

ghorbani shahna f, Bahrami A, Rotivand F, Salari S (2017): Evaluation the effects of using surfactants with sodium bicarbonate and limestone for the removal of sulfur dioxide in packed scrubber. Iran Occupational Health Journal 14, 162-151

Gray SM, Jarvis JB (2020): Process for removing so2 from flue gases using liquid sorbent injection. Google Patents

Han R, Sun F, Gao J, Wei S, Su Y, Qin Y (2017): Trace Na2CO3 Addition to Limestone Inducing High-Capacity SO2 Capture. Environmental science \& technology 51, 12692-12698

Jia Z, Liu Z, Zhao Y (2007): Kinetics of SO2 removal from flue gas on CuO/Al2O3 sorbent catalyst. Chemical Engineering \& Technology: Industrial Chemistry-Plant Equipment-Process EngineeringBiotechnology 30, 1221-1227

Keener TC, Khang S-J (1993): Kinetics of the sodium bicarbonate-sulfur dioxide reaction. Chemical Engineering Science 48, 2859-2865

Kimura S, Smith J (1987): Kinetics of the sodium carbonate-sulfur dioxide reaction. AIChE journal 33, 15221532

Kirk RE, Othmer DF, Mann CA (1949): Encyclopedia of Chemical Technology. Vol. II. The Journal of Physical Chemistry 53, 591-591

Knight JH (1977): The use of nahcolite for removal of sulfur dioxide and nitrogen oxides from flue gas. The Superior Oil Company

Liu C, Wang H (2019): Binary Diffusion Coefficients of Polycyclic Aromatic Hydrocarbons: A Molecular Dynamics Study.

Ma W, Haslbeck J (1993): NOXSO SO2/NOx flue gas treatment process Proof-of-Concept test. Environmental progress 12, 163-168

Mocek K, Beruto D (1986): On the morphological nature of $\mathrm{Na2CO}$ produced by thermal decomposition from $\mathrm{NaHCO} 3$ and from Na2CO3. $10 \mathrm{H} 2 \mathrm{O}$. Materials chemistry and physics $14,219-227$

Mortson M, Telesz RW (2001): Flue gas desulfurization using recycled sodium bicarbonate, The US EPA/DOE/EPRI Combined Power Plant Air Pollutant Control, The Mega Symposium. Citeseer

Moshiri H, Nasernejad B, Ebrahim HA, Taheri M (2014): A Comprehensive Kinetic Study of the Reaction of SO2 with $\mathrm{CaO}$ by the Random Pore Model. Chemical Engineering \& Technology 37, 2037-2046

Mousavi SE, Pahlavanzadeh H, Khani M, Ebrahim HA, Mozaffari A (2018): Selective catalytic reduction of SO 2 with methane for recovery of elemental sulfur over nickel-alumina catalysts. Reaction Kinetics, Mechanisms and Catalysis 124, 669-682

Petheram L (2002): Acid rain. Capstone

Ramachandran P, Doraiswamy L (1982): Modeling of noncatalytic gas-solid reactions. AIChE Journal 28, 881-900

Rashidi H, Ebrahim HA, Dabir B (2013): Application of random pore model for synthesis gas production by nickel oxide reduction with methane. Energy conversion and management 74, 249-260

Sohn HY, Kim B-S (2002): A novel cyclic reaction system involving CaS and CaSO4 for converting sulfur dioxide to elemental sulfur without generating secondary pollutants. 1 . Determination of process feasibility. Industrial \& engineering chemistry research 41, 3081-3086 
404

405

406

407

408

409

410

411

412

413

414

Stanislaus A, Marafi A, Rana MS (2010): Recent advances in the science and technology of ultra low sulfur diesel (ULSD) production. Catalysis today 153, 1-68

Tseng $\mathrm{H}-\mathrm{H}$, Wey M-Y (2004): Study of SO2 adsorption and thermal regeneration over activated carbonsupported copper oxide catalysts. Carbon 42, 2269-2278

Walawska B, Szymanek A, Pajdak A, Nowak M (2014): Flue gas desulfurization by mechanically and thermally activated sodium bicarbonate. Polish Journal of Chemical Technology 16, 56-62

Wu Y-L, Shih S-M (1993): Intrinsic kinetics of the thermal decomposition of sodium bicarbonate. Thermochimica acta 223, 177-186

Xu G, Luo G, Akamatsu H, Kato K (2000): An adaptive sorbent for the combined desulfurization/denitration process using a powder-particle fluidized bed. Industrial \& engineering chemistry research 39, 2190-2198

Yin H, Zhou T, Liu Y, Chai Y, Liu C (2011): NiMo/Al2O3 catalyst containing nano-sized zeolite Y for deep hydrodesulfurization and hydrodenitrogenation of diesel. Journal of natural gas chemistry 20, 441-448

\section{Tables}

08

09

\begin{tabular}{lccccc}
\hline \multicolumn{1}{c}{ Pellet } & $\bar{r}[\mathrm{~cm}]$ & $\varepsilon_{0}$ & $\begin{array}{c}\mathrm{S}_{0} \\
{[1 / \mathrm{cm}]}\end{array}$ & $\begin{array}{c}\mathrm{L}_{0} \\
{\left[1 / \mathrm{cm}^{2}\right]}\end{array}$ & $\psi$ \\
\hline Calcinated $\mathrm{Na}_{2} \mathrm{CO}_{3}$ & $1.92 \times 10^{-5}$ & 0.64 & $1.27 \times 10^{6}$ & $1.36 \times 10^{12}$ & 3.81 \\
\hline
\end{tabular}

Table 1- Structural parameters of calcinated $\mathrm{Na}_{2} \mathrm{CO}_{3}$ 
Table 3- Rate constants for $\mathrm{SO}_{2}$ removal reaction with $\mathrm{Na}_{2} \mathrm{CO}_{3}$ at various temperatures

\begin{tabular}{cccccccc}
\hline $\mathrm{T}\left({ }^{\circ} \mathrm{C}\right)$ & 100 & 125 & 150 & 175 & 200 & 225 & 250 \\
\hline$k_{\mathrm{s}}(\mathrm{m} / \mathrm{s})$ & $8.78 \times 10^{-6}$ & $2.68 \times 10^{-5}$ & $3.48 \times 10^{-5}$ & $5.35 \times 10^{-5}$ & $6.09 \times 10^{-5}$ & $6.65 \times 10^{-5}$ & $9.14 \times 10^{-5}$ \\
\hline
\end{tabular}

420

421

422

423

424

Table 4- RPM parameters for $\mathrm{Na}_{2} \mathrm{CO}_{3}+\mathrm{SO}_{2}$ reaction at $150{ }^{\circ} \mathrm{C}$

\begin{tabular}{cc}
\hline Parameter & Value \\
\hline $\mathrm{D}_{\mathrm{e} 0}\left[\mathrm{~m}^{2} / \mathrm{s}\right]$ & $2.13 \times 10^{-6}$ \\
$\mathrm{D}_{\mathrm{p}}\left[\mathrm{m}^{2} / \mathrm{s}\right]$ & $3.40 \times 10^{-18}$ \\
$\psi$ & 2.12
\end{tabular}

425

426

427

428

Table 5- The appropriate $D_{p}$ values for the reaction of $\mathrm{Na}_{2} \mathrm{CO}_{3}$ with $\mathrm{SO}_{2}$ at various temperatures

\begin{tabular}{cc}
\hline $\mathrm{T}\left({ }^{\circ} \mathrm{C}\right)$ & $D_{p}\left[\mathrm{~m}^{2} / \mathrm{s}\right]$ \\
\hline 100 & $1.25 \times 10^{-18}$ \\
125 & $3 \times 10^{-18}$ \\
150 & $3.4 \times 10^{-18}$ \\
175 & $3.95 \times 10^{-18}$ \\
200 & $6.6 \times 10^{-18}$ \\
225 & $8 \times 10^{-18}$ \\
250 & $1.5 \times 10^{-17}$ \\
\hline
\end{tabular}



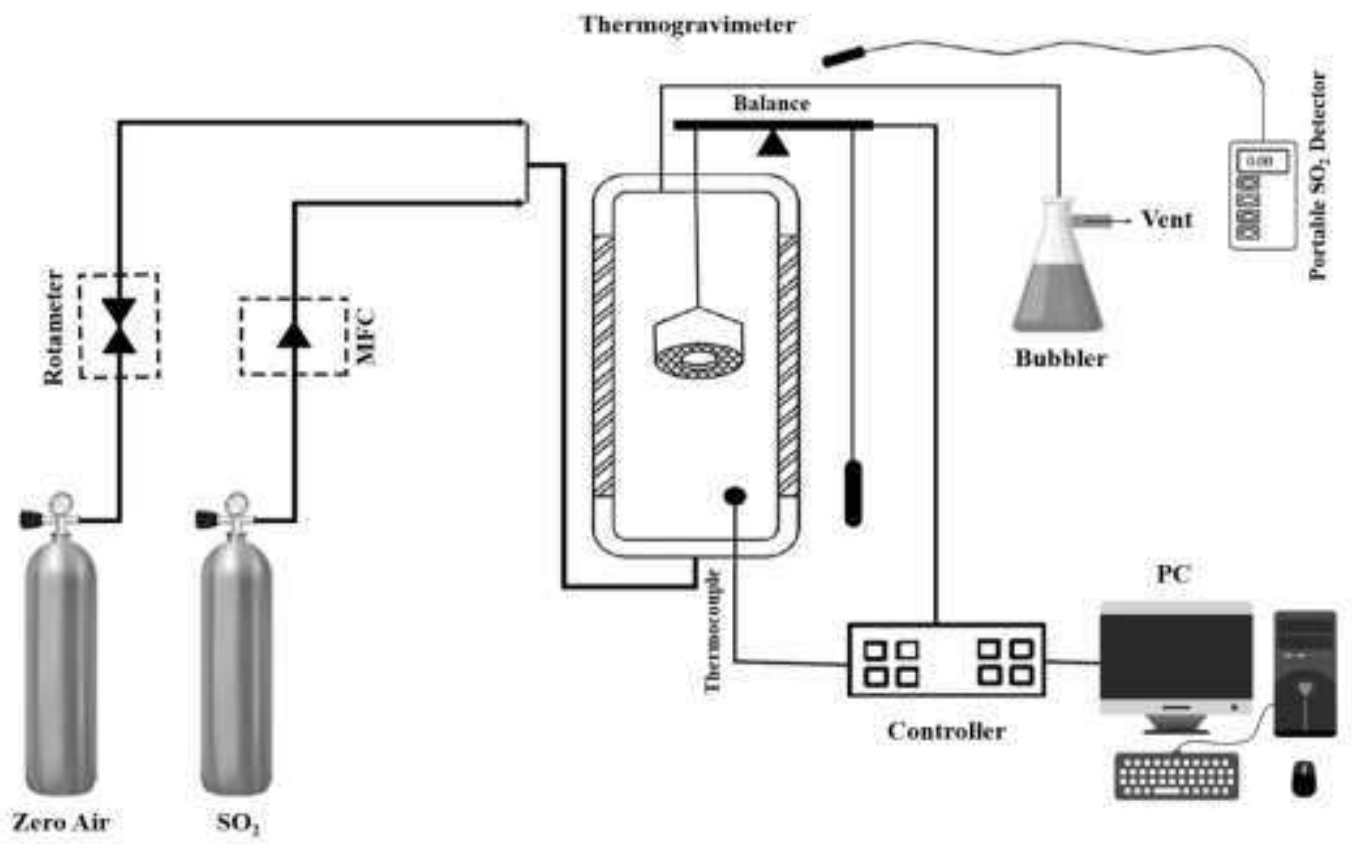

Fig. 1: A schematic diagram of the experimental setup

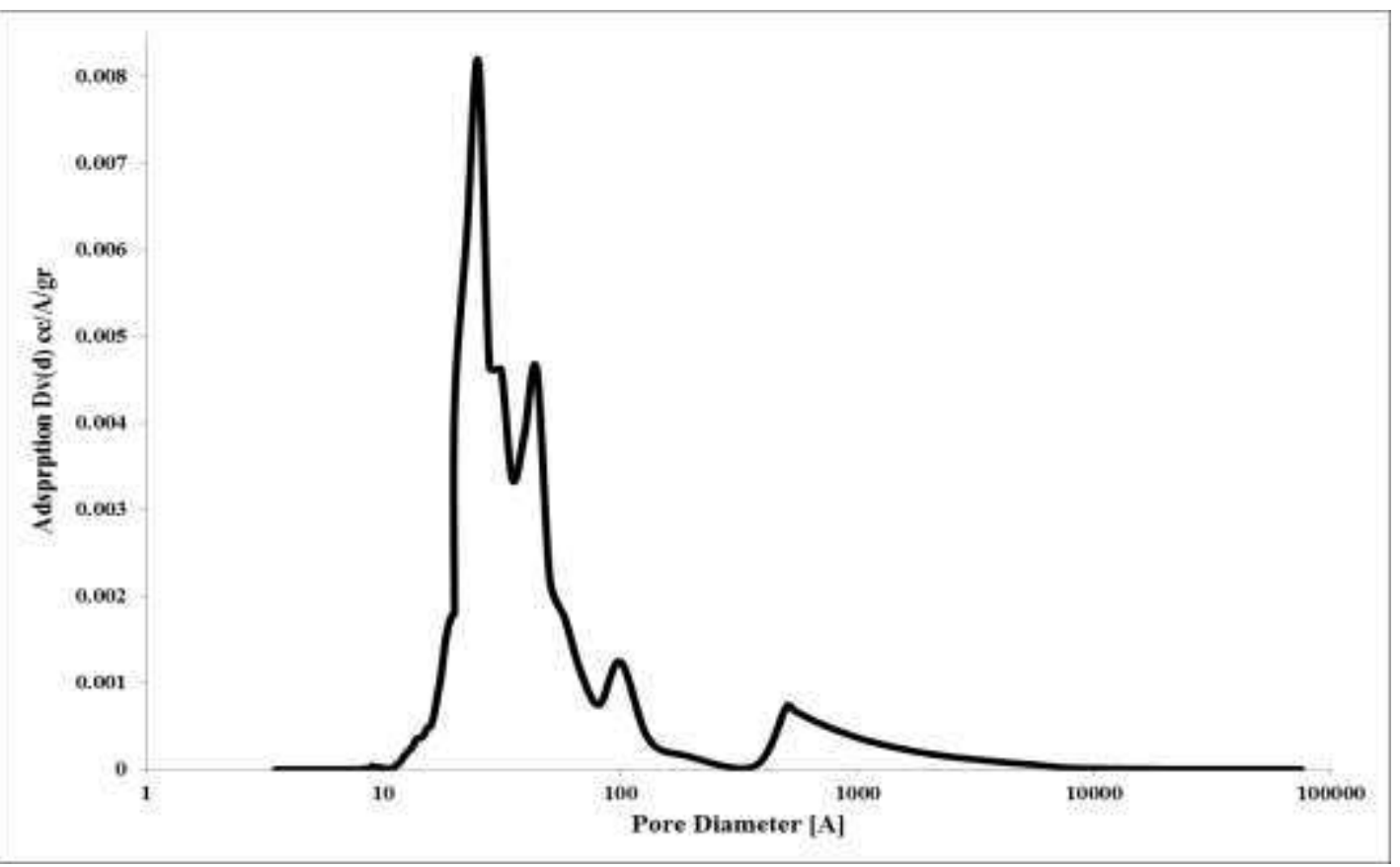

Fig. 2: The whole PSD for $\mathrm{Na}_{2} \mathrm{CO}_{3}$ pellet 

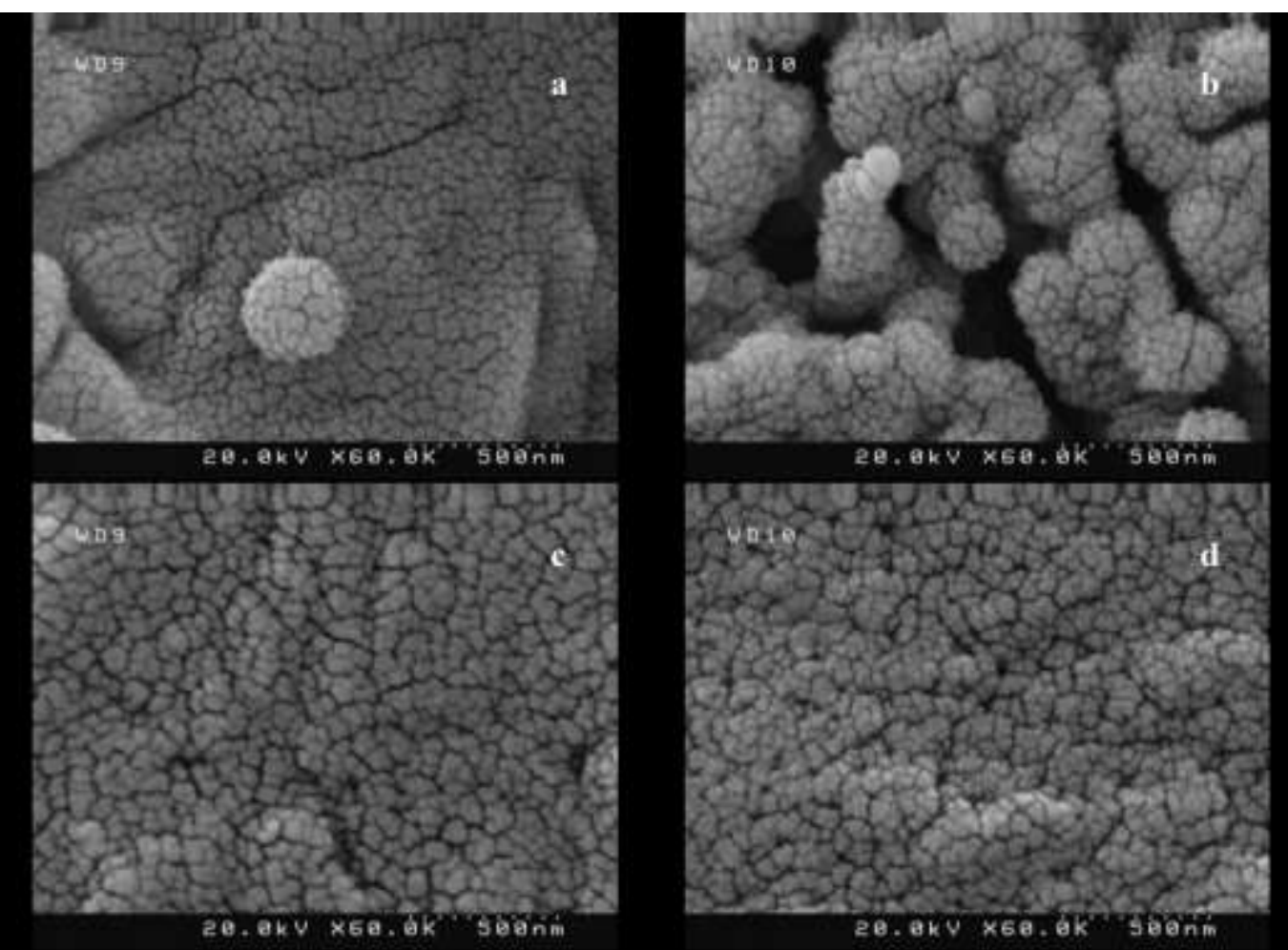

Fig. 3: SEM images of the sample (a) before calcination, (b) after calcination at $150{ }^{\circ} \mathrm{C}$, (c) after reaction with $\mathrm{SO}_{2}$ at 150 ${ }^{\circ} \mathrm{C}$, (d) after reaction with $\mathrm{SO}_{2}$ at $225{ }^{\circ} \mathrm{C}$

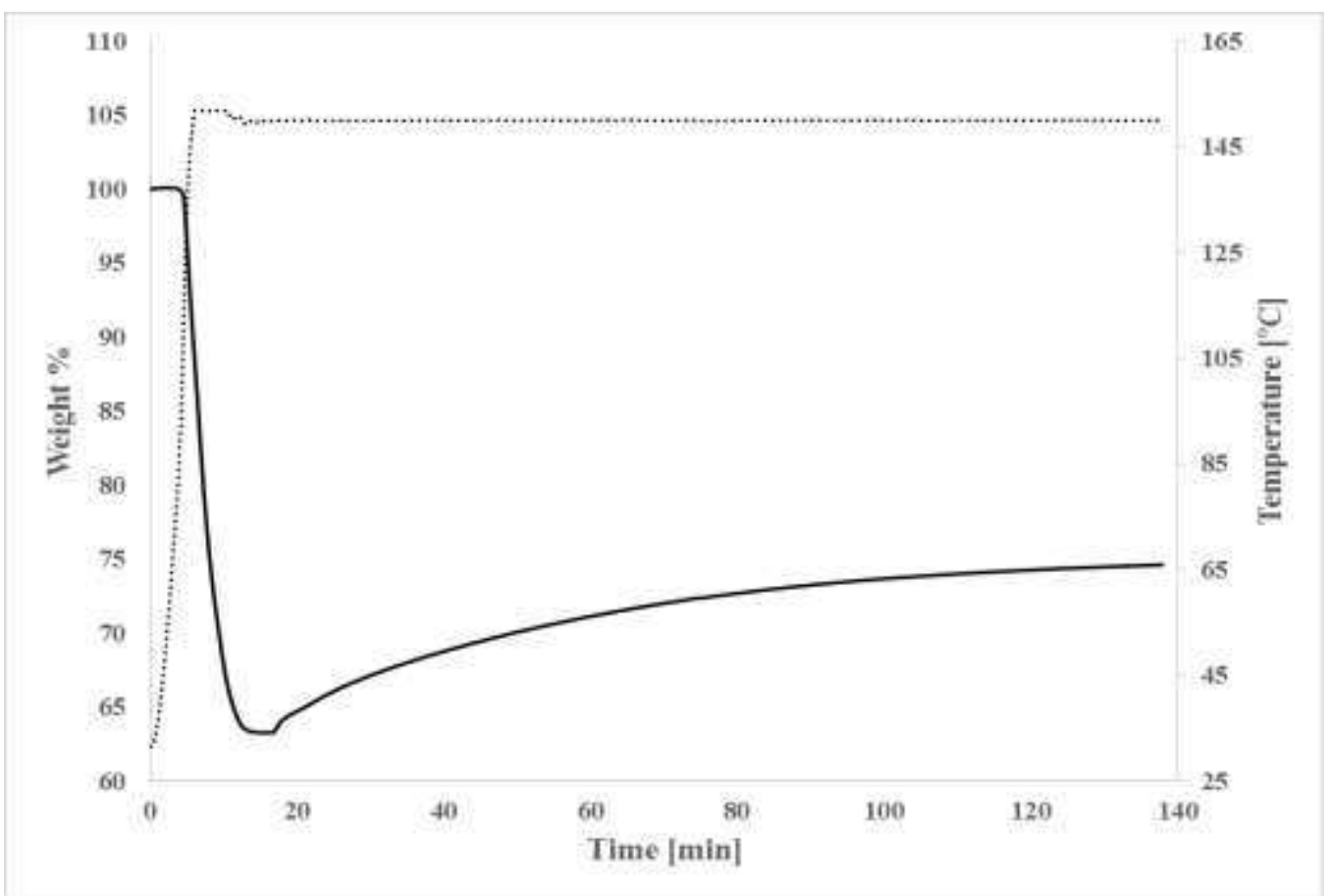




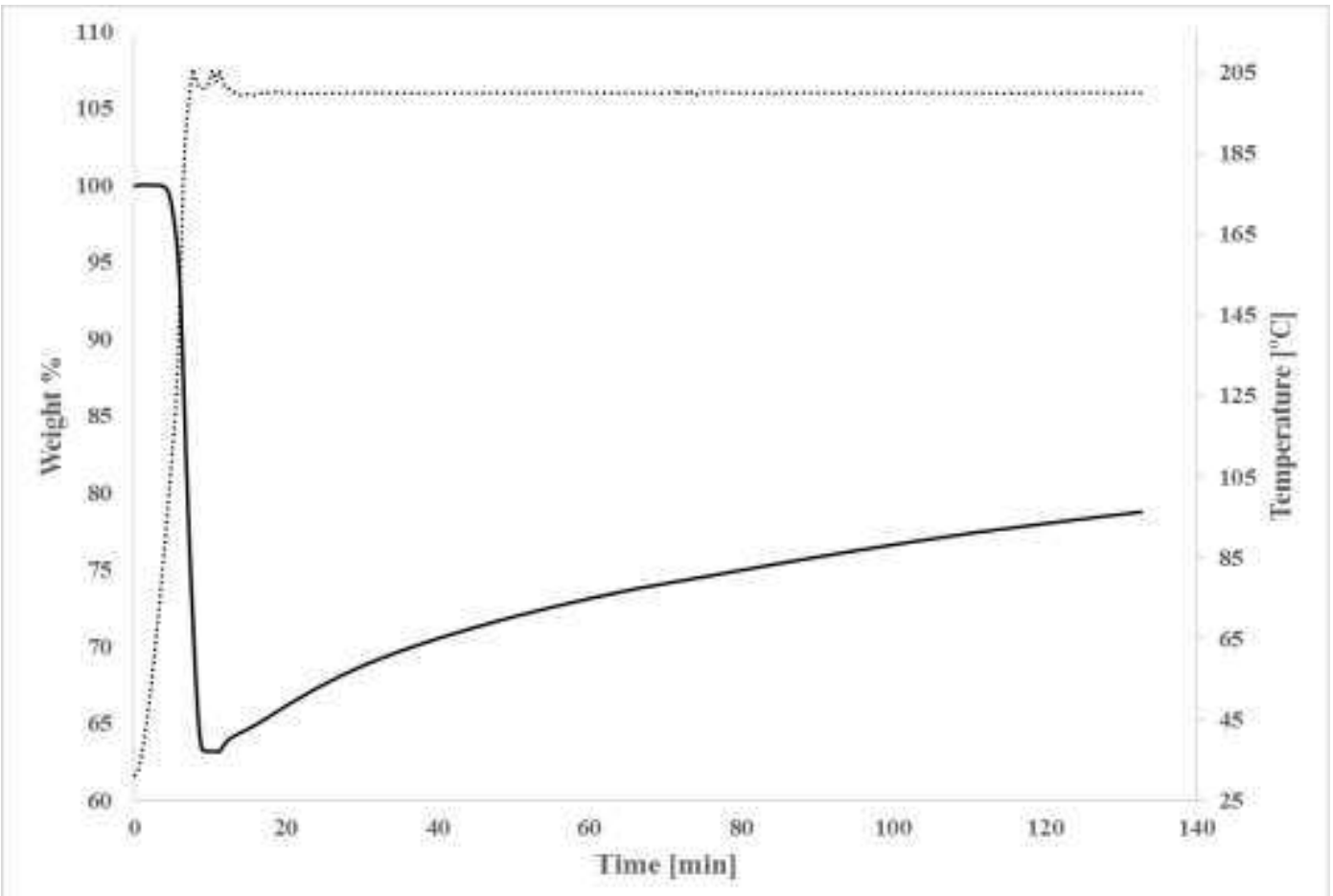

445

Fig. 5: TG curve for sodium bicarbonate calcination and its subsequent reaction at $200{ }^{\circ} \mathrm{C}$ and 0.66 vol. $\% \mathrm{SO}_{2}$

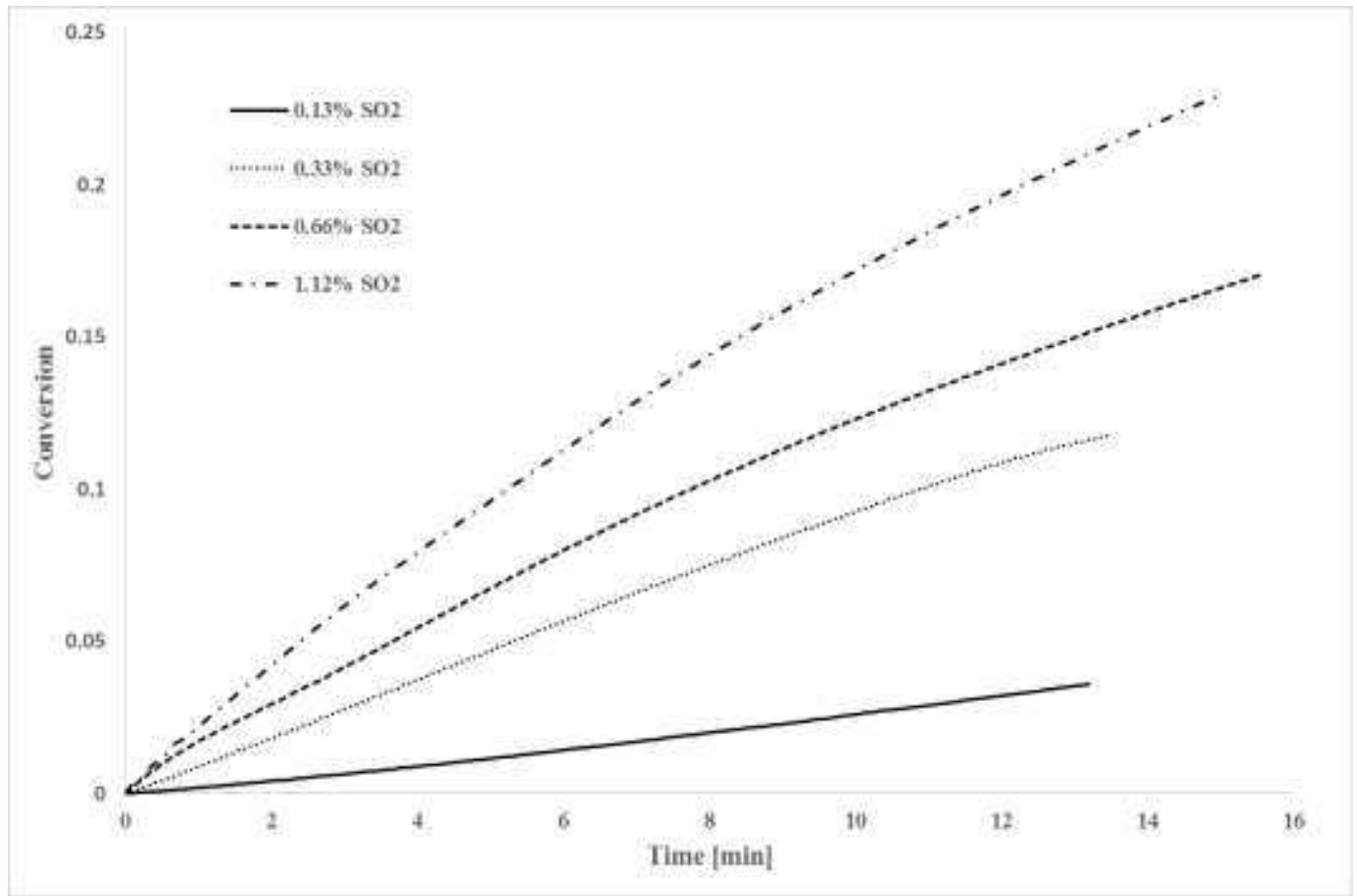

Fig. 6: Effect of $\mathrm{SO}_{2}$ concentration on reaction at $150{ }^{\circ} \mathrm{C}$ 


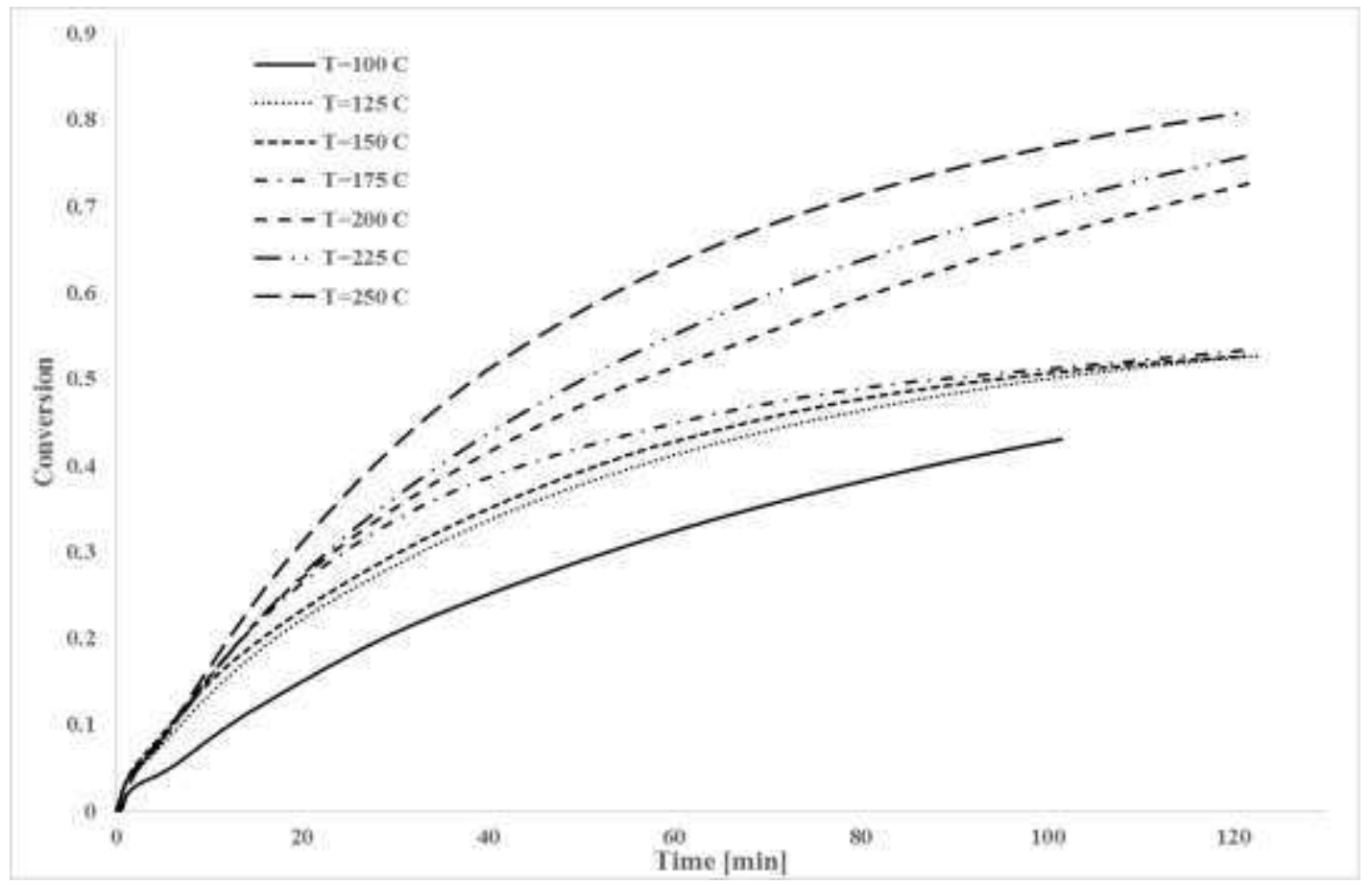

Fig. 7: Effect of temperature on reaction at 0.66 vol\% $\mathrm{SO}_{2}$

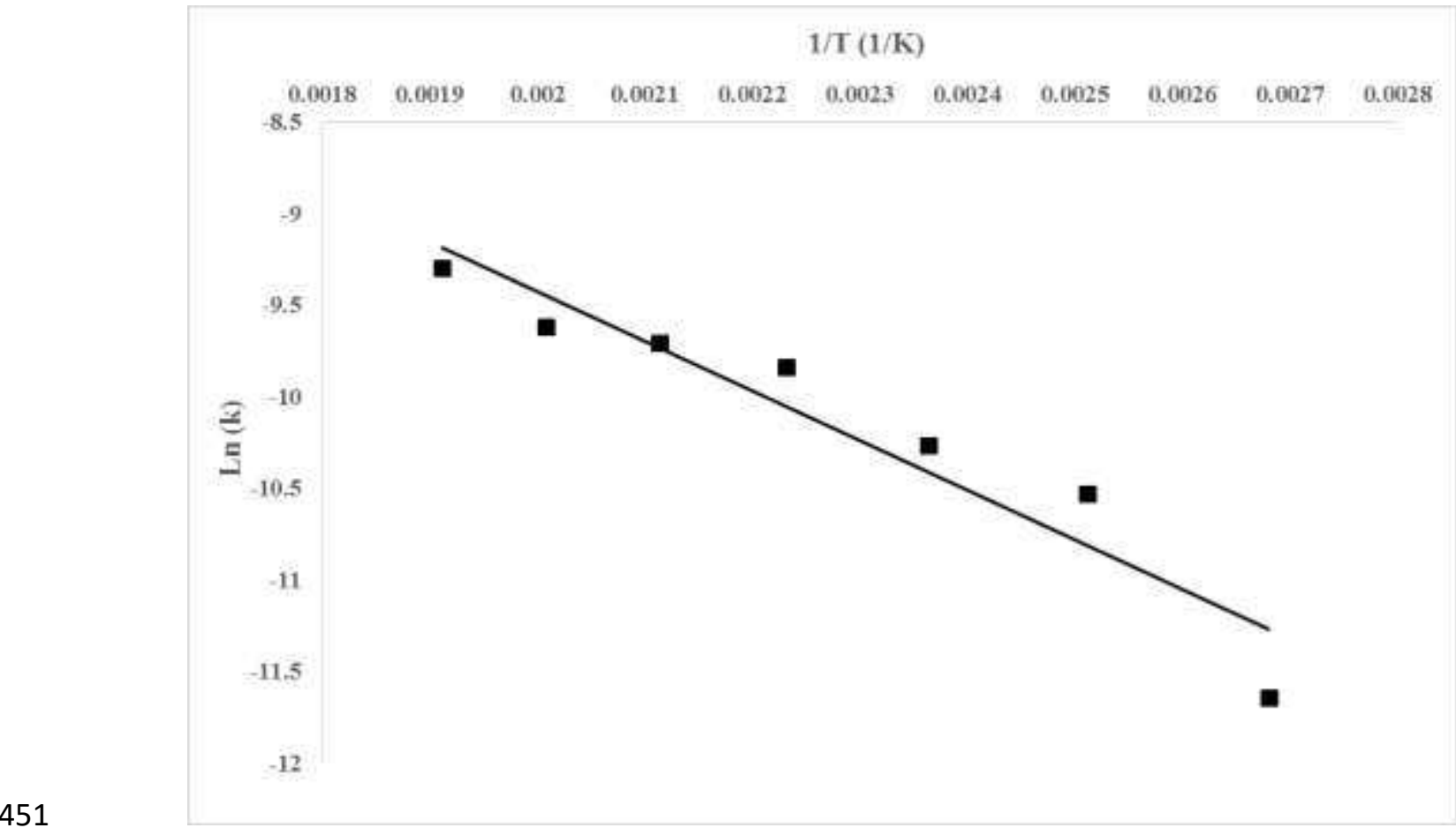

Fig. 8: Arrhenius plot on the generated rate constant values 

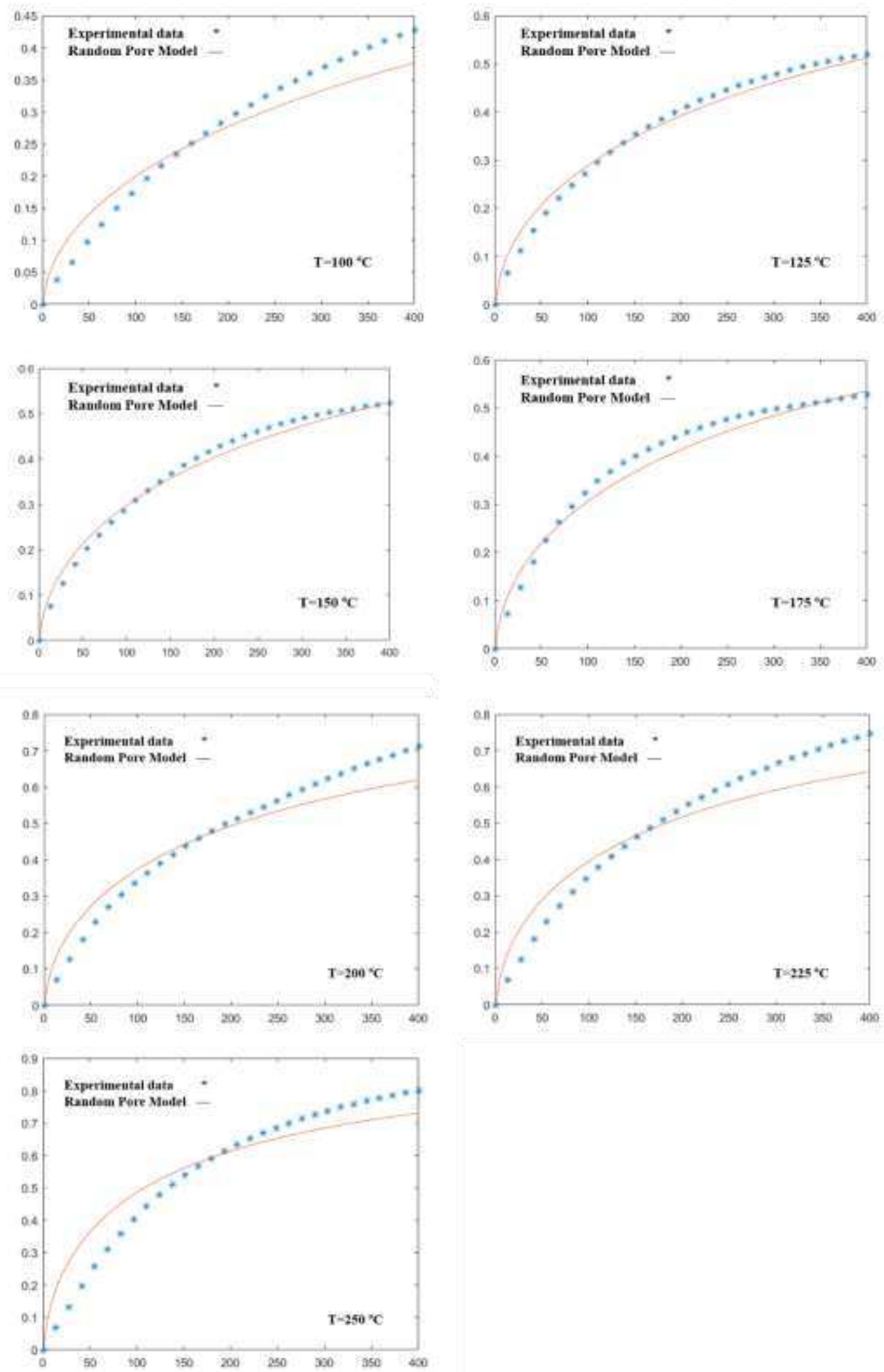

Fig. 9: Comparison between predicted data of RPM and experimental data at various temperatures and 0.66 vol\% $\mathrm{SO}_{2}$ 


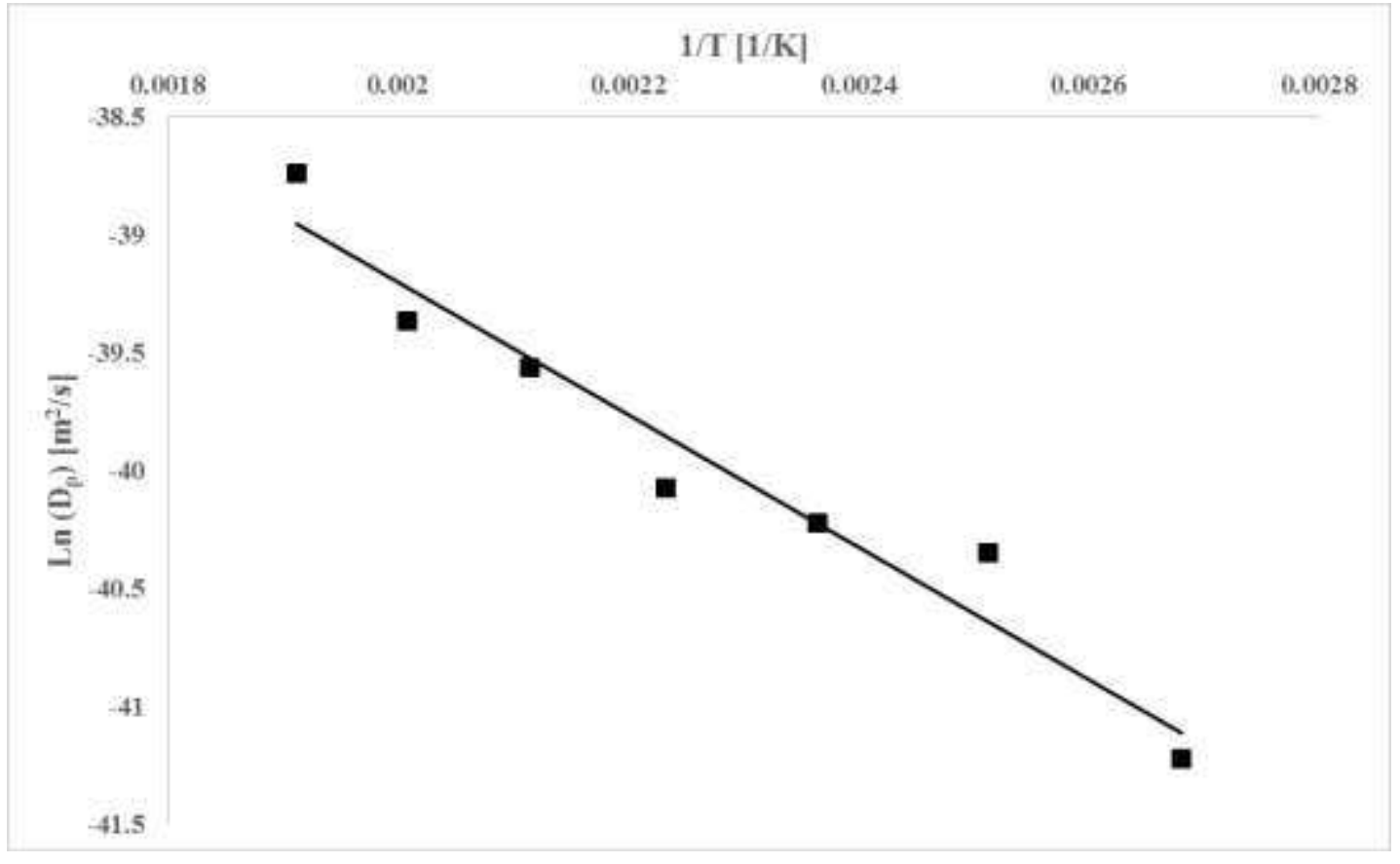

Fig. 10: Arrhenius plot on the generated diffusion coefficient values 


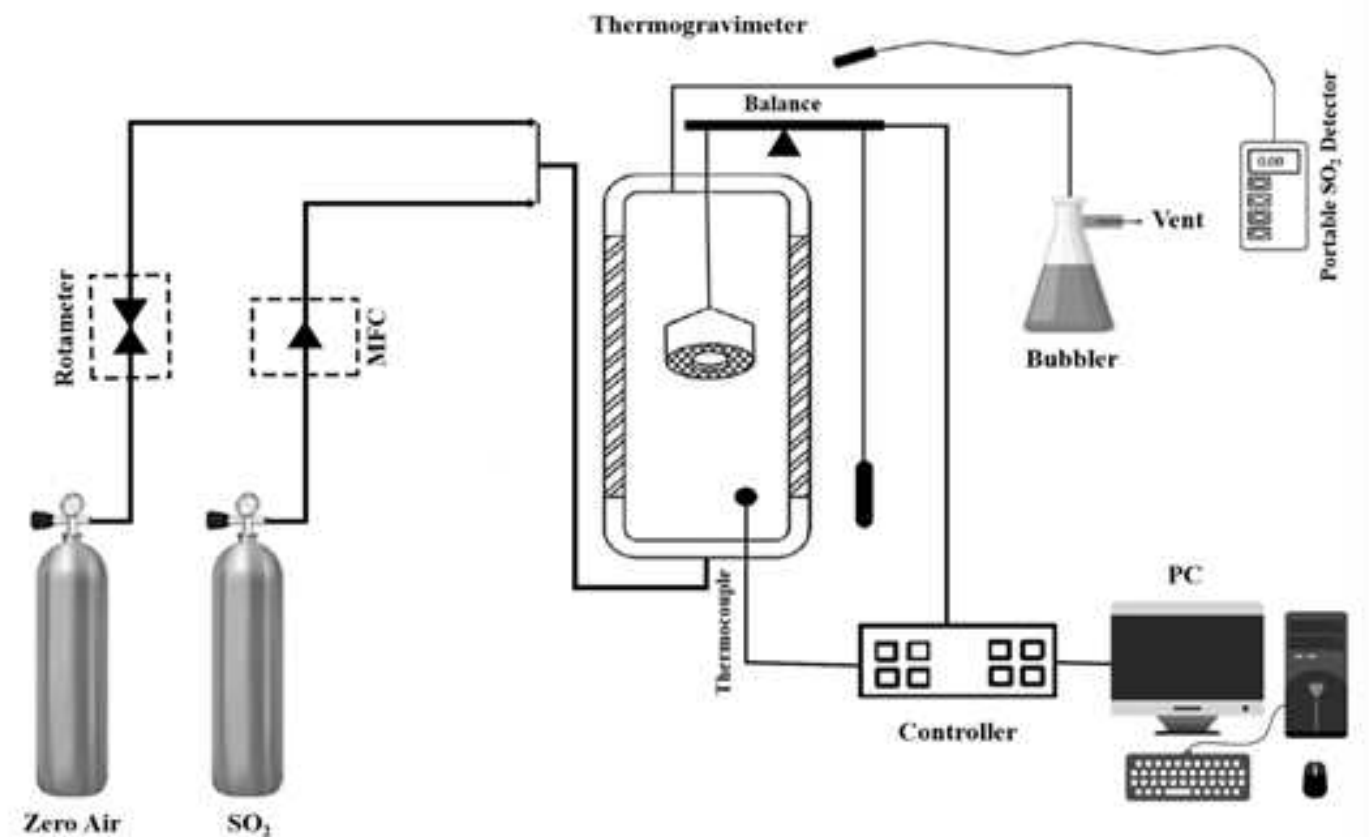

Figure 1

A schematic diagram of the experimental setup

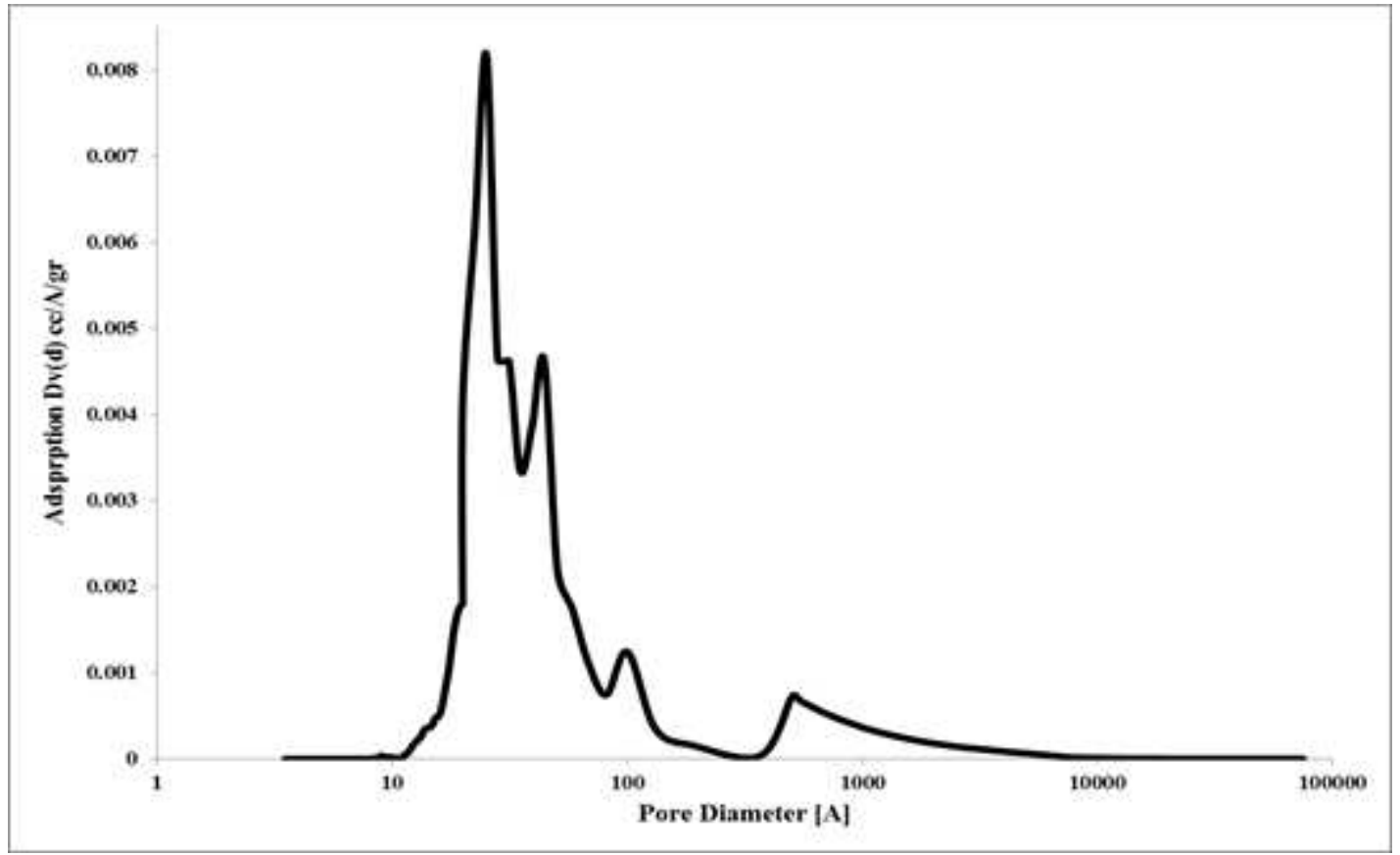

Figure 2

The whole PSD for $\mathrm{Na} 2 \mathrm{CO} 3$ pellet 


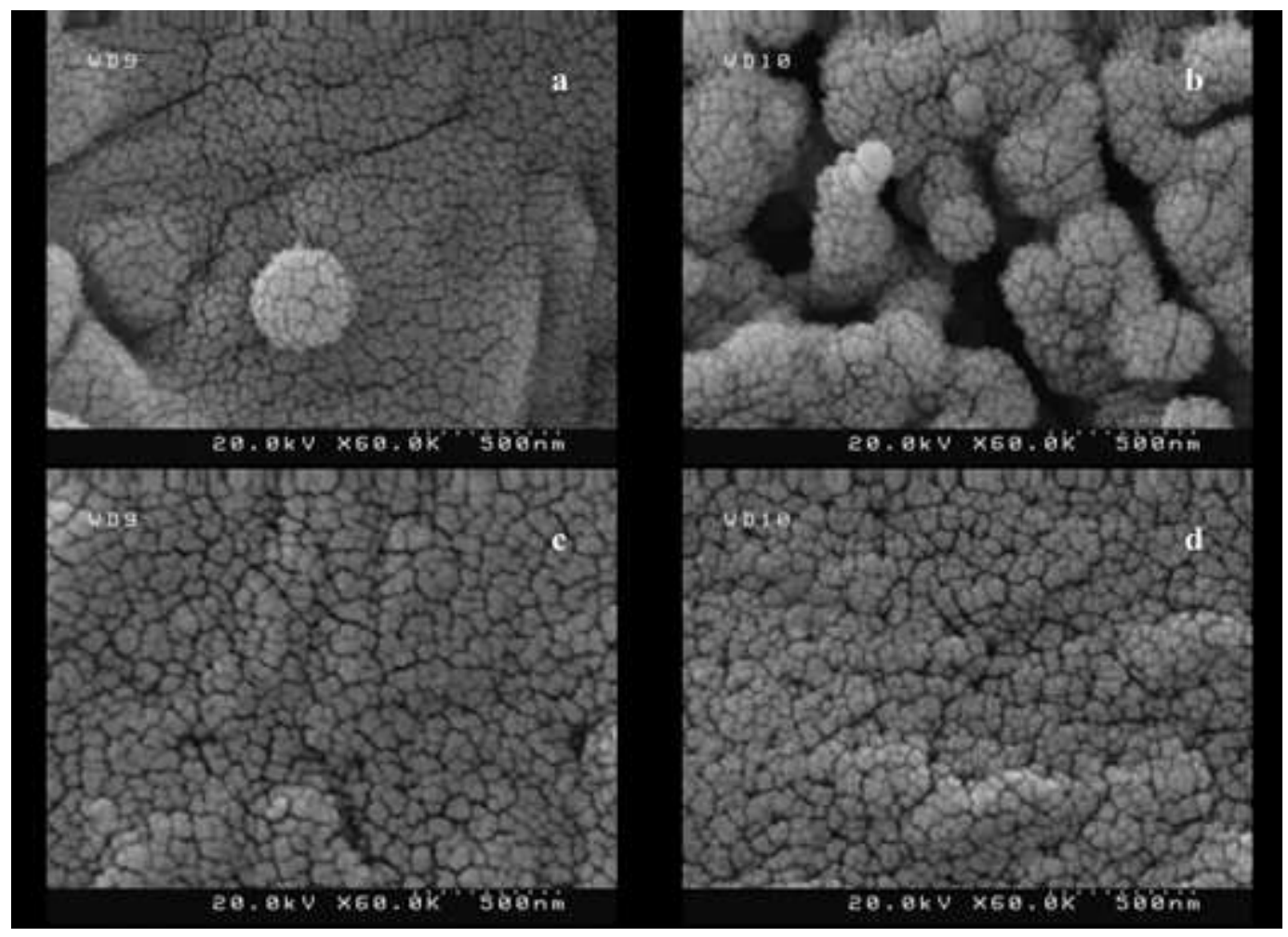

\section{Figure 3}

SEM images of the sample (a) before calcination, (b) after calcination at $150 \mathrm{oC}$, (c) after reaction with SO2 at 150 oC, (d) after reaction with SO2 at 225 oC

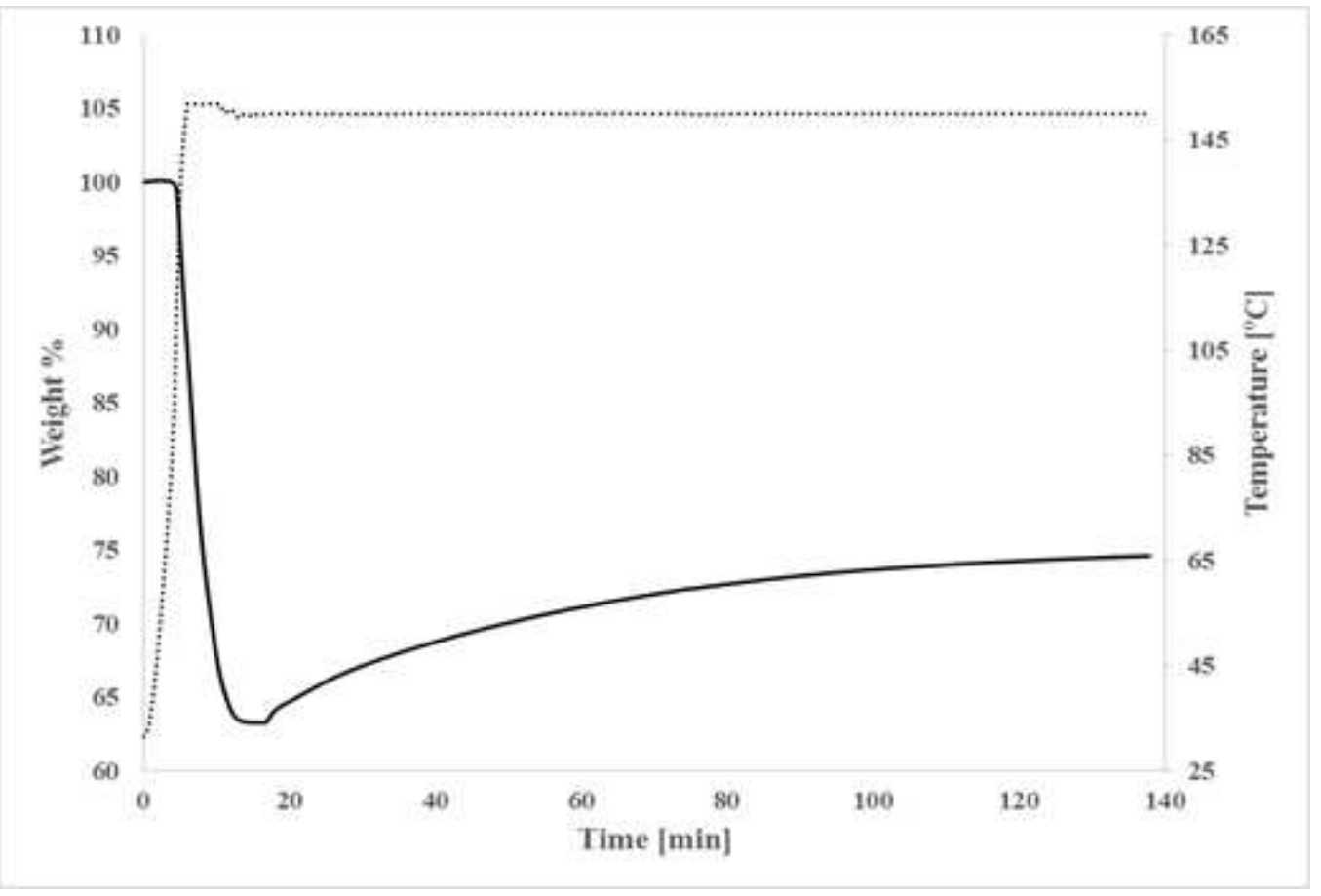

\section{Figure 4}

TG curve for sodium bicarbonate calcination and its subsequent reaction at 150 oC and 0.66 vol.\% SO2 


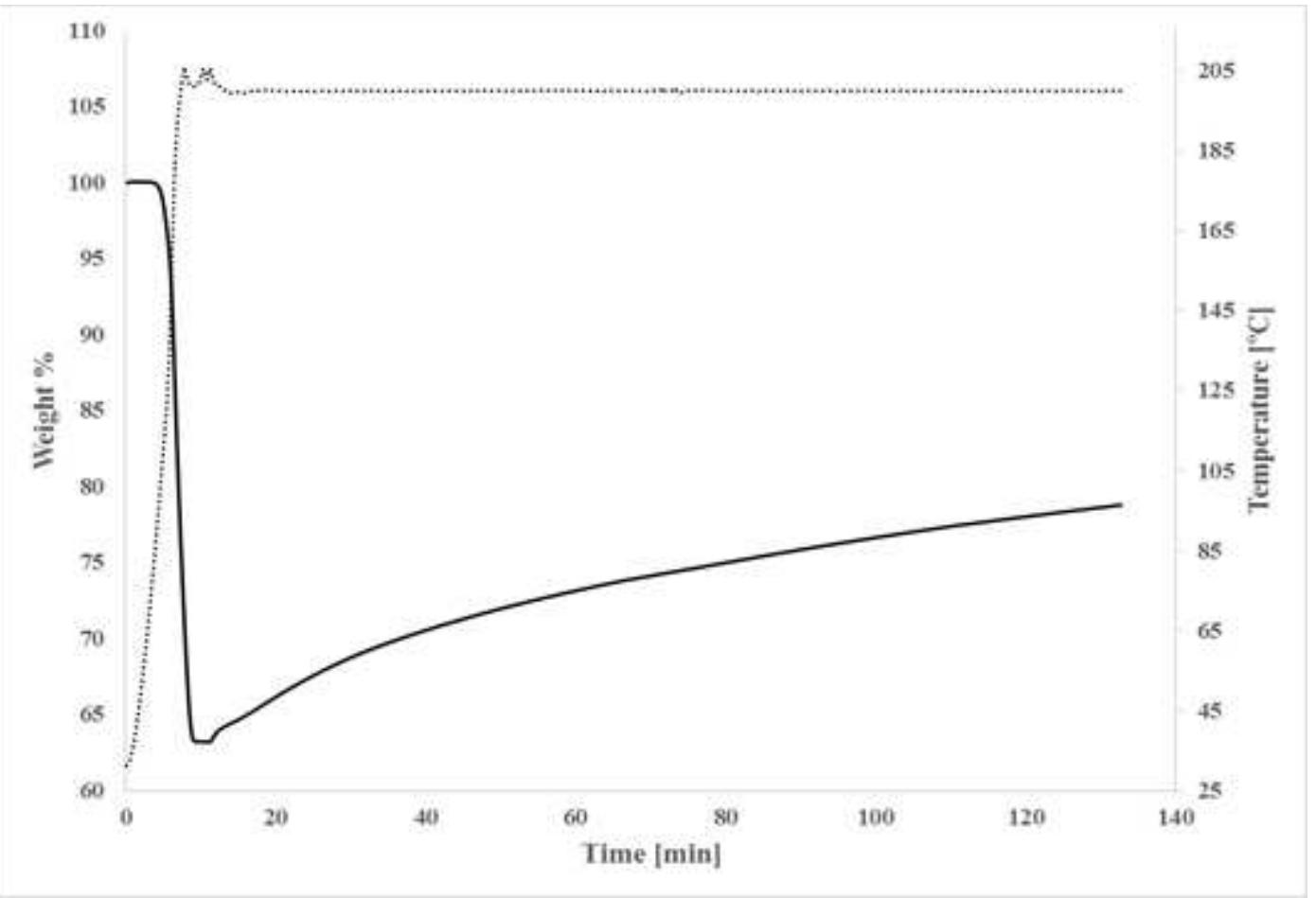

Figure 5

TG curve for sodium bicarbonate calcination and its subsequent reaction at $200 \mathrm{oC}$ and 0.66 vol.\% SO2

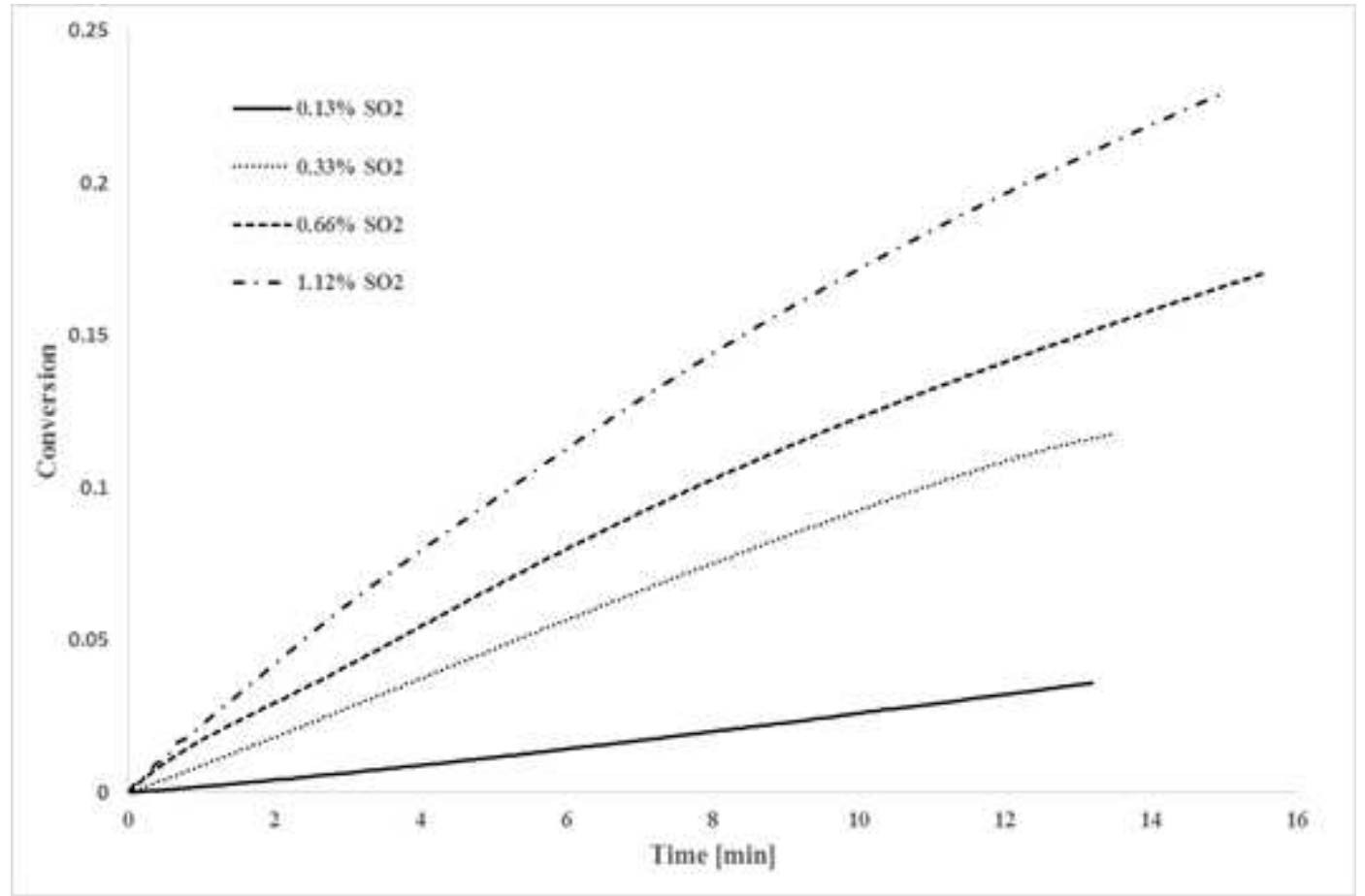

Figure 6

Effect of SO2 concentration on reaction at 150 oC 


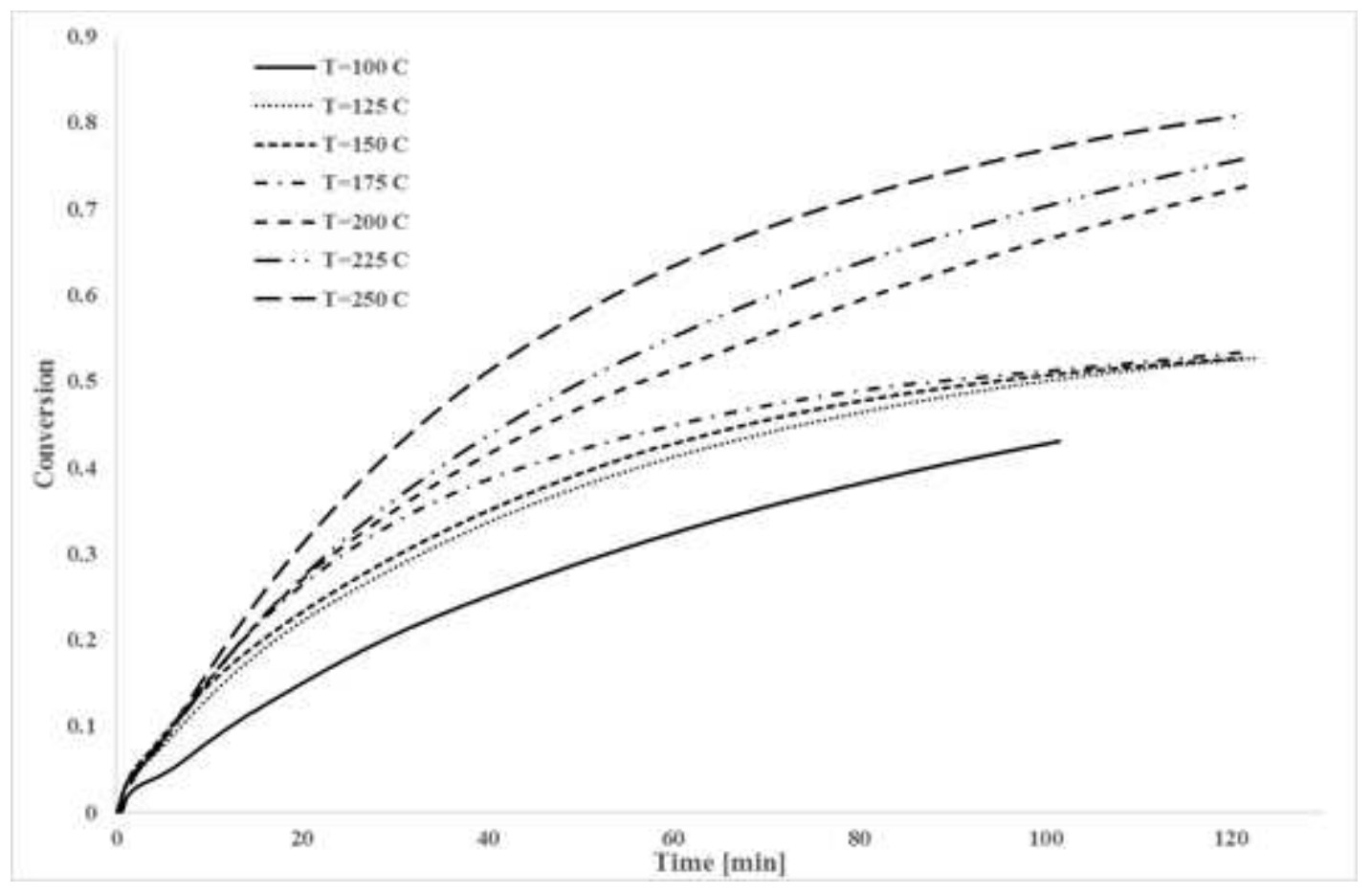

Figure 7

Effect of temperature on reaction at 0.66 vol\% SO2

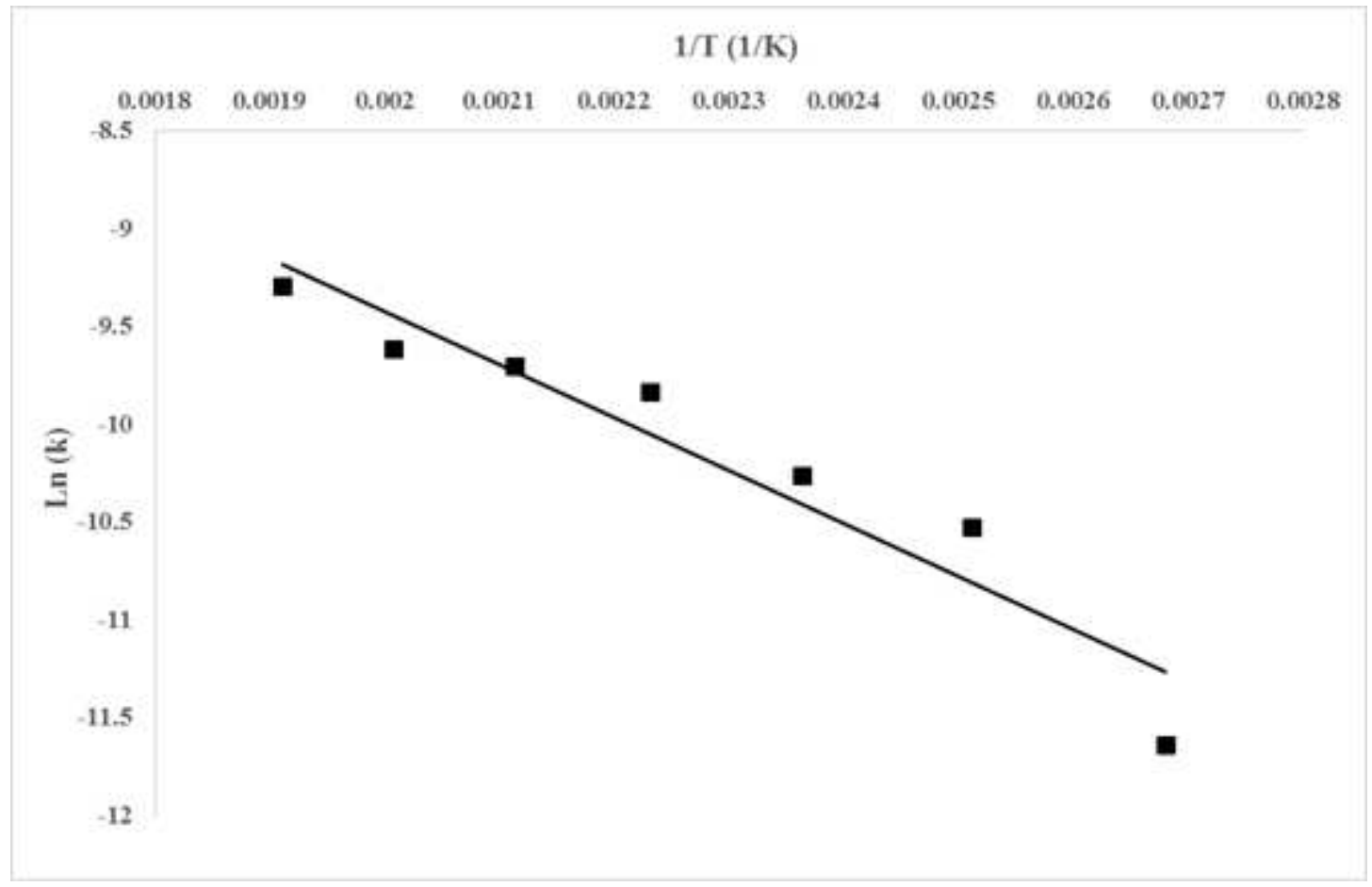

Figure 8

Arrhenius plot on the generated rate constant values 

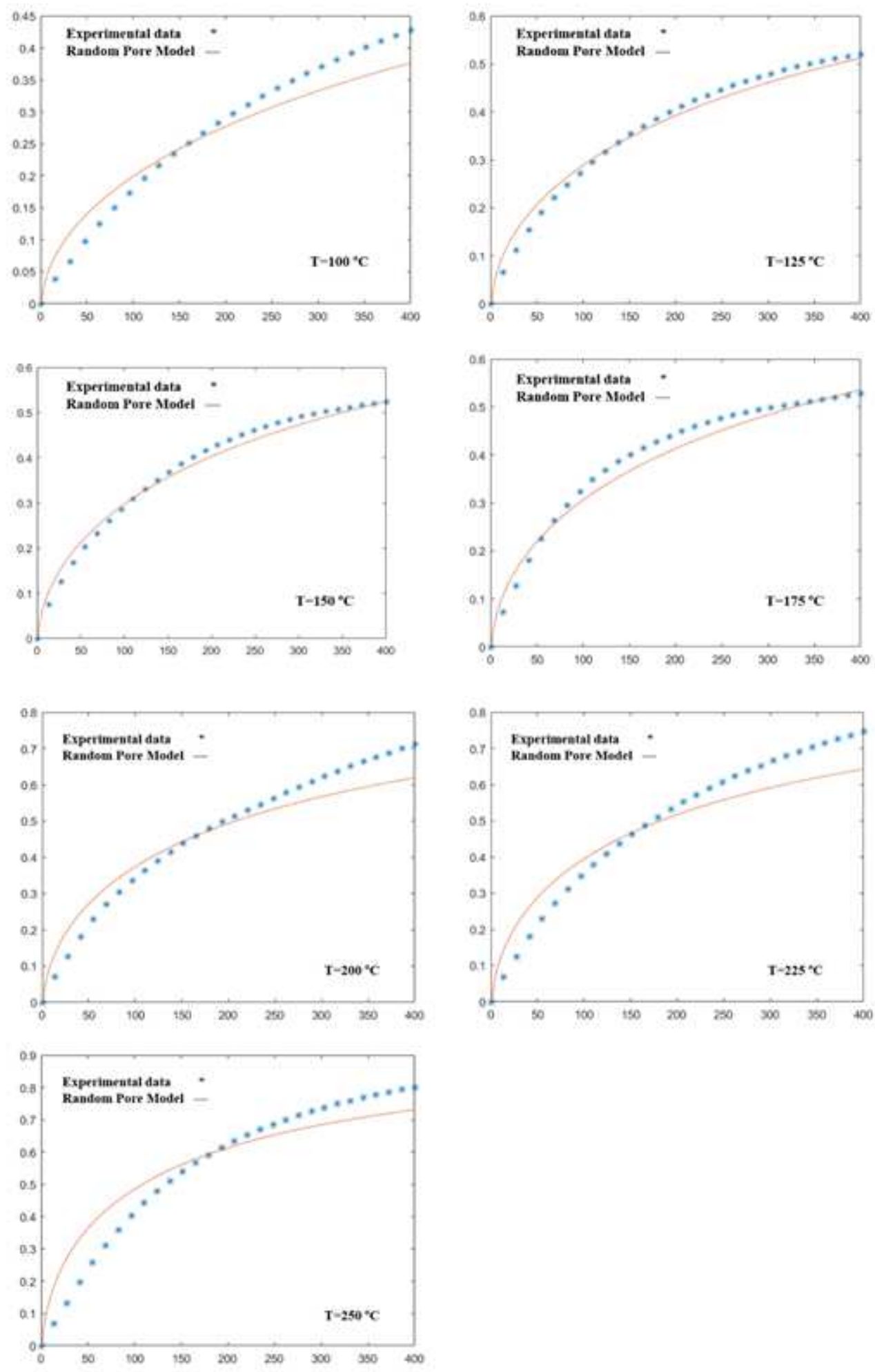

Figure 9

Comparison between predicted data of RPM and experimental data at various temperatures and 0.66 vol\% SO2 


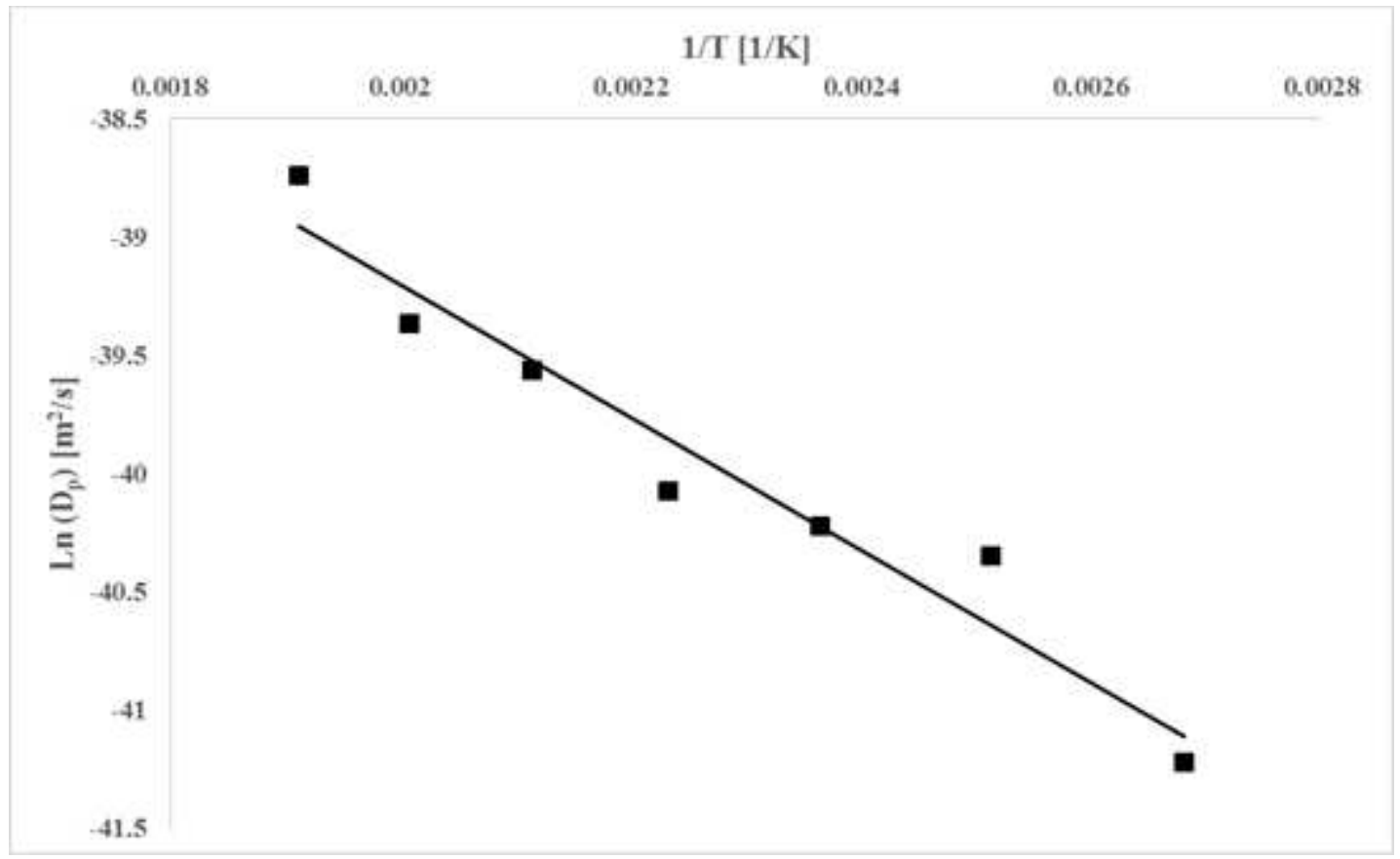

Figure 10

Arrhenius plot on the generated diffusion coefficient values 